Document downloaded from:

http://hdl.handle.net/10251/64785

This paper must be cited as:

Bermúdez Tamarit, VR.; Lujan Martinez, JM.; Climent Puchades, H.; Campos, D. (2015). Assessment of pollutants emission and aftertreatment efficiency in a GTDi engine including cooled LP-EGR system under different steady-state operating conditions. Applied Energy. 158:459-473. doi:10.1016/j.apenergy.2015.08.071.

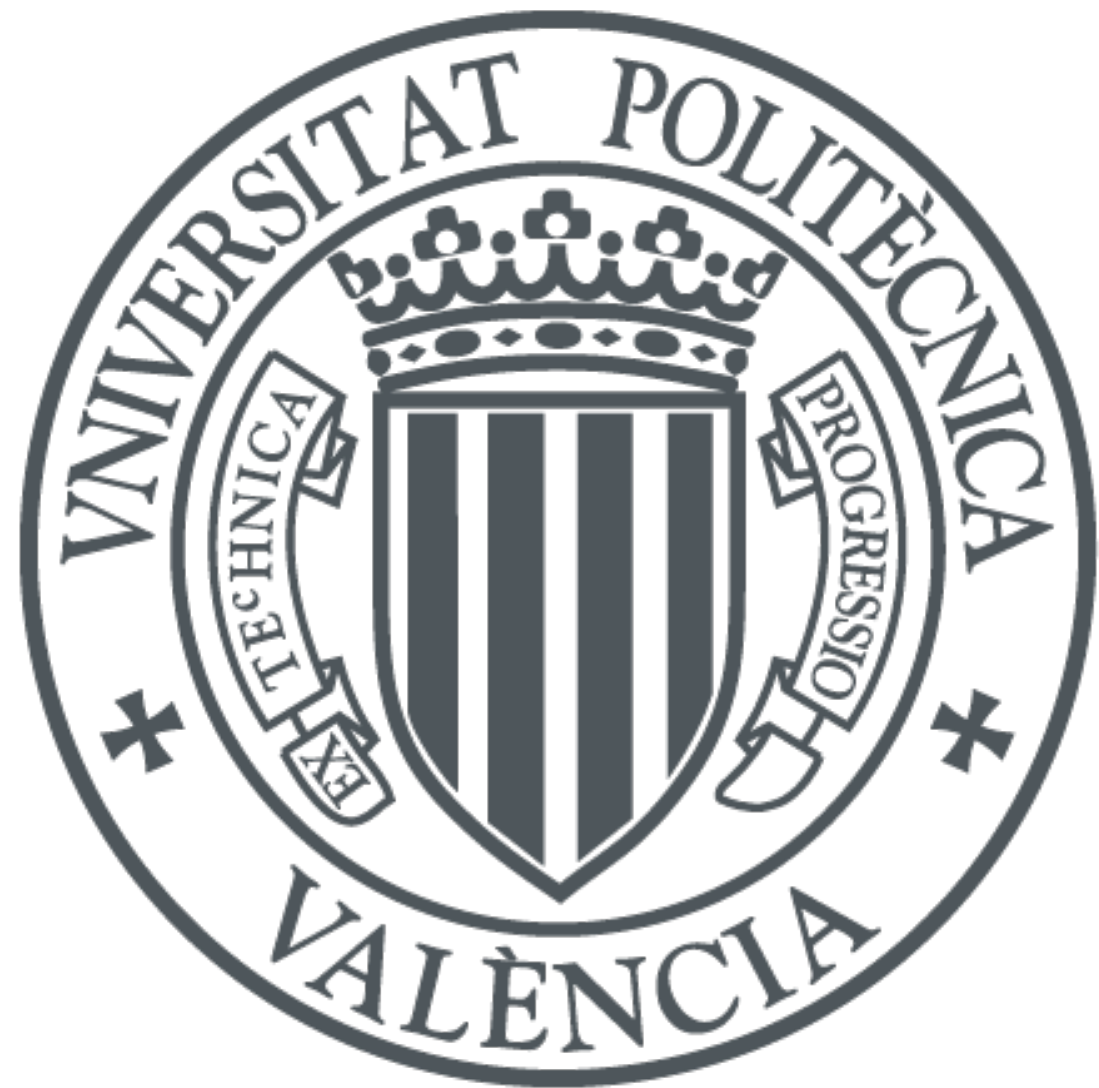

The final publication is available at

http://dx.doi.org/10.1016/j.apenergy.2015.08.071

Copyright Elsevier

Additional Information 


\title{
Assessment of pollutants emission and aftertreatment efficiency in a GTDi engine including cooled LP-EGR system under different steady-state operating conditions
}

\author{
Vicente Bermúdez *, José Manuel Luján, Héctor Climent, Daniel Campos \\ Universitat Politècnica de València, CMT-Motores Térmicos, Camino de Vera s/n, 46022 Valencia, Spain.
}

\begin{abstract}
Nowadays, EGR systems are being incorporated in the research focused on spark-ignition direct-injection engines as a solution to the problems presented by them; i.e. knock risk and high combustion temperature which produces high NOx emission. Since the major part of the investigations are centered on engine performance or engine simulation aside pollutants emission and aftertreatment evaluation, this paper focuses on these topics: gaseous and particle emission analysis and aftertreatment efficiency evaluation when cooled LP-EGR system is applied to a GTDi engine.

This work has been performed in a 4-cylinder, turbocharged, direct-injection gasoline engine with $2.0 \mathrm{~L}$ displacement. The equipment used in this study are TSI-EEPS for particle measurement and HORIBA MEXA 1230-PM for soot measurement being HORIBA MEXA 7100-DEGR with a heated line selector the system employed for regulated gaseous emission measurement and aftertreatment evaluation. A reduction around 50\% of NOx with an increase of $\mathrm{HC}$ and $\mathrm{CO}$ emissions was found in medium-load operating points. At full-load conditions, the suppression of fuel enrichment including EGR leads in a drastically reduction in CO maintaining similar HC and NOx emissions. Furthermore, PN and soot emissions also decrease as EGR is included and spark timing advanced in all the tested conditions.
\end{abstract}

Keywords: GTDi engine, LP-EGR system, particle and soot emission analysis, gaseous emission, TWC efficiency

\section{Introduction}

In engine evolution, standards limits concerning pollutants emitted into the atmosphere by internal combustion 3 (IC) engines are becoming more restrictive in the European Union [1]. During the last decade, the limits in gaseous 4 emission have been progressively reduced at different compounds: carbon monoxide (CO), nitrogen oxides (NOx) 5 and unburned hydrocarbons (HC); and more recently in the limit of mass of particulate matter (PM) emitted. This 6 reduction in pollutant limits have been applied in both spark-ignition (SI) and compression-iginition (CI) engines.

\footnotetext{
*V. Bermúdez. CMT-Motores Térmicos, Universitat Politècnica de València, Camino de Vera s/n, 46022 Valencia, Spain. Phone: +34963877650 Fax: +34963877659 e-mail: bermudez@mot.upv.es
} 
Due to these restrictions in emitted pollutants and the increasing awareness on reducing fuel consumption, numerous studies are being aimed to fuel consumption optimization [2].

For improving fuel economy, turbocharged direct-injection gasoline (GTDi) engines are becoming the substitutes to the traditional port fuel injected (PFI) gasoline engines [3, 4]. Normally, GTDi engines can be operated through two different combustion modes, stratified or homogeneous [5]. In stratified combustion, the fuel vaporizes as combustion occurs and the air-to-fuel (AF) ratio in the cylinder is not thoroughly mixed. This allows for reduced fuel consumption at idle and low load conditions, along with the ability to run the engine un-throttled. The homogeneous combustion mode allows the engine to operate with a more uniform AF mixture inside the cylinder. Homogeneous combustion is necessary for moderate to high loads and peak power [6].

The reduction in fuel consumption is mainly due to the improvements carried out in atomization and vaporization fuel process through high pressure (200 bar) injection systems, being highly popular in world market since they are increasing downsizing and power density [7]. However, the decrease in the time to prepare AF mixture before ignition process and fuel deposition on the piston walls during fuel injection lead to an increase of particle emission at GTDi engines $[8,9]$. In this way, numerous studies have shown the connection of particles emitted by reciprocating IC engines with epidemiological and toxicological problems [10, 11]. Therefore recently the European Commission has regulated the particle number $(\mathrm{PN})$ that can be emitted by reciprocating IC engines during the homologation cycle [12].

The main problems presented by this engine type are due to the high power density, which is directly translated into higher knock risk and high exhaust temperatures produced in combustion chamber [13]. On the one hand, knock phenomenon occurs when certain portion of cylinder charge has not burned through the turbulent flame but the reaction rate reaches levels where the spontaneous auto-ignition occurs [14]. Thus, an appropriate control of knock risk is becoming increases importance. On the other hand, the increase in power density leads to higher temperatures in combustion chamber, so an increase in NOx formation is observed [15].

As a solution for reducing knock risk and the high combustion temperature, different strategies have been adopted such as: (i) decreasing effective compression ratio, (ii) injecting excessive fuel in the mixture (fuel enrichment) to decrease AF, or (iii) incorporating exhaust gas recirculation (EGR) systems [16]. The extended strategy adopted is the excessive fuel in $\mathrm{AF}(\lambda<1)$ to decrease combustion temperature, so an increase in both fuel consumption and HC and $\mathrm{CO}$ emission is produced through this method. Other disadvantage of this method is the worst performance of the three way catalyst (TWC), which is the commonly aftertreatment device used in SI engines. The TWC best efficiency is achieved under stoichiometric conditions, so fuel enrichment produces high pollutants emission.

However, nowadays the interest of scientific community is focusing on EGR systems as a solution to the problems of knock risk and high combustion temperature in GTDi engines [17-19]. This strategy, which is commonly used in Diesel engines [20], is becoming used in gasoline engines together with other techniques [21]. Furthermore, related to the problem in the performance of the aftertreatment device, the use of EGR as a diluent gas can allow the use of an 
overall stoichiometric charge, which produces high conversion efficiency at TWC. In this regard, EGR is considered the main method to reduce knock risk, combustion temperature [22], fuel consumption [23] and NOx emission [24].

In order to keep constant the torque and mechanical power provided by the engine when EGR is applied, a wide opening of engine throttle becomes necessary to improve the density of the intake charge, reducing pumping losses and improving fuel economy [25]. Focusing on the differences between hot or cool EGR, diverse authors have shown that cooled EGR has more benefit than hot EGR [26]. In this regard, cooled EGR increases volumetric efficiency through the increase of the intake charge density and also improve NOx emission but worsening HC emission and cycle-to-cycle variations [27]. Naturally, the introduction of EGR at full-load deteriorates the combustion process as well as the volumetric efficiency, so spark-plug timing optimization becomes necessary in order to improve torque demand [28].

While the reduction in PM and NOx emissions have been studied in the past, the present paper makes a significant contribution to the field for its holistic approach. In the literature, several studies have been focused on particle measurement in PFI engines including EGR systems and assessing different EGR ratios [13, 29-31]. Other studies realized with GTDi engines were focused on performance analysis when EGR is added but leaving out particle measurements $[16,19,22,23,32,33]$, or focusing on particle measurements including different gasoline blends [9, 28, 30, 34]. In this sense, it is uncommon to find all these topics included in the same research paper, being this issue the main contribution of this work. Therefore, the necessity for provide a complete exhaust gas emissions behavior when different EGR ratios have been assessed in a GTDi engine is increasing regarding new emission standards limits around the world. Concerning these issues, exhaust emissions (regulated gaseous compounds, soot emission, and particulate size distribution) were analyzed in four different steady state operating points with a wide range of EGR rates in this work. The study also includes a catalytic efficiency analysis and the influence of the EGR rate in engine performance such as fuel consumption and exhaust temperature

\section{Material and methods}

In this section a general description of the engine main characteristics, as well as the main properties of the fuel used are detailed. In addition, both complete resume of the different equipment used in the research instrumentation and the test methodology are given.

\subsection{Test bench facilities and fuel used}

The engine used in this study was a 4-cylinder, turbocharged, direct-injection SI engine with 2.01 displacement including a serial TWC aftertreatment downstream the turbine which complies with Euro 5 standards. Fuel injectors have a seven holes nozzle and were placed between the intake valves at $45^{\circ}$ with respect to the vertical cylinder axis, as it is show in Figure 1. The fuel pressure system was supplied by Bosch manufacturer and was capable for allow injection pressures up to $15 \mathrm{MPa}$. This engine is mounted in a typical passenger car, and detailed specifications of the 
engine are given in Table 1. The engine was installed in a fully instrumented test cell, with all the auxiliary facilities required for its operation and control.

A custom-made LP-EGR system was added since original engine did not included this EGR line. The exhaust gas was extracted from TWC outlet and recirculed to the compressor inlet, allowing homogenous mixture gas at the intake manifold [33]. The LP-EGR line design was made incorporating an intercooler which allows control in EGR gas temperature, followed by a control valve which controls the EGR rate.

A commercial gasoline with a Research Octane Number (RON) of 98 was used in all the engine tests being the specifications of the fuel properties provided in Table 2.

The engine was connected to a dynamometric brake SCHENCK DYNAS3 LI250, which allows instant speed and torque engine control. In order to make possible modifications in spark-plug timing (SP) the Engine Control Unit (ECU) was partially opened and the engine setting maps can be recalibrated with the ETAS-INCA software. The test bench was fully equipped with $\mathrm{K}$ thermocouples and mean pressure sensors in the exhaust, cooling, intake and lubricating system. The engine instrumentation includes sensors to measure the main magnitudes defining the engine performance, such as air mass flow, fuel mass flow, and engine speed and torque. In this regard, the characteristics and the error of the instrumentation of the engine used in this work are summarized in Table 3.

\subsection{Experimental Set-up}

Three different analyzers were used in this study for measuring particles, soot and pollutants emission as it is shown Figure 2.

For regulated gaseous emission measurement, an HORIBA MEXA 7100D-EGR was installed to provide both raw and tailpipe emissions, and EGR ratio through the $\mathrm{CO}_{2}$ measurements, as it will be explained in the next Section. In order to establish a quantification of the efficiency of the aftertreatment device, a heated valve system concept was installed to assess the TWC conversion during the steady-state operating points.

For particle measurement, TSI-EEPS was employed in order to allow particle size distribution (PSD) [35]. TSIEEPS is capable for measuring PSD with a frequency up to $1 \mathrm{~Hz}$ providing a measurement range between 5.6 to $560 \mathrm{~nm}$. The methodology used to sample exhaust aerosol from tailpipe and measure PSD in transient conditions, which is also applicable to steady state conditions, was performed in the laboratory according to Desantes et al. [36] as shown in Figure 3. The dilution system used in this study was a DEKATI-FPS 4000 and it dilutes the exhaust sample in two stages. A porous tube (PTD) is used as the isothermal primary diluter (A to B way in Figure 3) and a subsequent ejector diluter (ED) acts as the secondary diluter (B to $\mathrm{C}$ way in Figure 3).

Finally, an HORIBA MEXA 1230-PM which includes a TSI-DCS100 was used to provide the soot emission rate. The system consists of a diffusion charging sensor (DCS) with a specific dilution device for soot measurement [37] being the dilution ratio settled according to Bermúdez et al. [38].

In order to give a detailed characterization of the devices used, Table 4 shows the range and the measurement sensitivity of each pollutant measured. 


\subsection{Calculations method}

The brake specific fuel consumption (BSFC) is calculated as the relation between the brake power and fuel consumption, defined in Equation (1).

$$
B S F C=\frac{m_{f u e l}}{P_{e}}
$$

As widely adopted, EGR rate was calculated from $\mathrm{CO}_{2}$ concentrations taken at the intake and exhaust manifolds. Equation (2) defines the calculated EGR rate as:

$$
E G R_{\text {rate }}=\frac{\left[\mathrm{CO}_{2, \text { int. }}\right]-\left[\mathrm{CO}_{2, \text { atm. }}\right]}{\left[\mathrm{CO}_{2, \text { exh. }}\right]-\left[\mathrm{CO}_{2, \text { atm. }}\right]} \cdot 100
$$

In Equation (2), $\left[\mathrm{CO}_{2, \text { int }}\right]$ is the $\%$ Vol. of $\mathrm{CO}_{2}$ measured at the intake manifold being $\left[\mathrm{CO}_{2, \text { exh }}\right]$ the $\%$ Vol. of $\mathrm{CO}_{2}$ taken at exhaust manifold. Atmospheric carbon dioxide was considered as $\left[\mathrm{CO}_{2, \mathrm{~atm}}\right]$.

The method adopted for conversion efficiency calculation was based on Equation (3):

$$
T W C_{\text {eff. }}=100-\frac{\left[X_{\text {down }}\right]}{\left[X_{\text {up }}\right]} \cdot 100
$$

In Equation (3), $\left[X_{\text {down }}\right]$ and $\left[X_{u p}\right]$ are the each gaseous pollutant emissions downstream and upstream the TWC respectively.

In order to obtain good accuracy in the separation of accumulation-mode, particle size distributions may be decomposed by Equation (4), according to Seinfeld and Pandis [39]. It establishes that total particle size distribution is the sum of both particle mode cocentrations, assuming the log-normal size distribution function:

$$
\begin{aligned}
\frac{d N_{i}}{d \log d p_{i}} & =\frac{1-x}{\sqrt{2 \pi} \log \sigma_{g 1}} \exp \left[-\frac{\log ^{2}\left(\frac{d p_{1}}{d p_{g 1}}\right)}{2 \log ^{2} \sigma_{g 1}}\right]+ \\
& +\frac{x}{\sqrt{2 \pi} \log \sigma_{g 2}} \exp \left[-\frac{\log ^{2}\left(\frac{d p_{2}}{d p_{g 2}}\right)}{2 \log ^{2} \sigma_{g 2}}\right]
\end{aligned}
$$

In Equation (4), $x$ is the ratio of the total concentrations number of two distributions, $d p_{1}, d p_{2}, d p_{g 1}, d p_{g 2}, \sigma_{g 1}$ and $\sigma_{g 2}$ are the geometric mean diameters, median diameters, and geometric standard deviations of each peak, and $N_{i}$ is the particle concentration of particle size $d p_{i}$. The fit is achieved by minimizing the mean square error function by means of the Nelder-Mead simplex method. Several studies proposed the limits of the nucleation-mode between 30 and $50 \mathrm{~nm}$ [40]. In this study, the decomposition of particle size distribution is nucleation-mode particles from 5.6 to $30 \mathrm{~nm}$; and accumulation-mode particles from 30 to $560 \mathrm{~nm}$.

To calculate total particle number concentration and geometric mean diameter (GMD) the Equations (6) and (5) respectively are used for each mode: 


$$
\begin{array}{r}
d N=\sum_{d p(\text { low })}^{d p(\text { up })} d N_{i} \\
G M D=\frac{\sum_{d p(\text { low })}^{d p(\text { up })} d N_{i} \ln d p_{i}}{d N}
\end{array}
$$

\subsubsection{Results variability analysis}

The variability and the significance of the measurement were calculated through StatGraphics software. In the following list the sequence to obtain means representative values and their deviation are descripted.

- For each day and each measurement, mean values and its coefficient of variation (COV) of raw data collected were firstly calculated.

$$
\begin{aligned}
& \bar{x}_{d a y, 1} \pm C O V_{d a y, 1} \\
& \bar{x}_{d a y, 2} \pm C O V_{d a y, 2} \\
& \bar{x}_{d a y, 3} \pm C O V_{d a y, 3}
\end{aligned}
$$

- The total mean value (TMV) was calculated as mean of the three means of each day being the value represented at each point in the graphs.

$$
T M V=\frac{\bar{x}_{d a y, 1}+\bar{x}_{d a y, 2}+\bar{x}_{d a y, 3}}{3}
$$

- The maximum and minimum variation of each TMV was adopted calculating the maximum or minimum variation of the three COVs calculated.

$$
\begin{aligned}
\operatorname{Max}_{\text {var. } .}= & \operatorname{Maximum}\left(\bar{x}_{d a y, 1}+C O V_{d a y, 1} ;\right. \\
& \left.\bar{x}_{d a y, 2}+\operatorname{COV} V_{d a y, 2} ; \bar{x}_{d a y, 3}+C O V_{d a y, 3}\right)-T M V \\
\operatorname{Min}_{v a r .}= & T M V-\operatorname{Minimum}\left(\bar{x}_{d a y, 1}-C O V_{d a y, 1} ;\right. \\
& \left.\bar{x}_{d a y, 2}-\operatorname{COV} V_{d a y, 2} ; \bar{x}_{d a y, 3}-C O V_{d a y, 3}\right)
\end{aligned}
$$

Thus, the points showed at each plot are the TMV $\pm \underset{\operatorname{Min}_{\mathrm{var}} \text {. }}{\operatorname{Max}}$ 


\subsection{Test schedule}

In order to assess a detailed analysis of pollutants emission in a wide range of engine speed and load, four steadystate operating points were tested. Thus, two of these engine operating points were selected according to lambda engine map obtaining a representative steady-state operating points including fuel enrichment at different levels as Figure 4 shows. Concerning the EGR rate tested for each steady-state operating point, 5\%,10\% and $15 \%$ of exhaust gas recirculation rate are explored for all cases, except at $3000 \mathrm{rpm}$ full-load, where only 5\% and 10\% EGR rates could be possible to asses due to the strongly combustion damage at 15\% EGR rate. Further specifications for each steady-state operating points including different EGR rates are detailed in Table 5.

It is interesting to note that the steady-state operating points were selected for medium to full-load, so homogeneous combustion strategy (i.e. fuel injection is carried out during the intake stroke) was adopted for the start of injection (SOI) according to diverse authors [41-43]. This is similar to the strategy adopted in PFI engines, but performing EGR in this engine type has no benefits at full load and high engine speeds since volumetric efficiency is compromised. On the contrary, in the turbocharged architecture it is possible to perform EGR in these engine operating conditions to avoid fuel enrichment in order to limit the gas temperature at the inlet of the turbine. In this situation it is possible to add the EGR without a reduction on the air mass flow since the wastegate of the turbine can be operated. At partial loads, in both engine configurations the EGR inclusion can be performed by opening the engine throttle to recover the air mass flow

\subsubsection{Methodology for testing steady-state operating points}

For testing different EGR ratios at each engine speed and load, the methodology shown in Figure 5 was employed. This methodology was used in order to minimize the test-to-test variations being descripted below:

- The engine was running at reference steady-state condition (engine speed and torque). The time until perform the measurements was determined by the variation at TWC outlet temperature. In this sense, when this temperature was stable, the measurements were carried out during two minutes at $1 \mathrm{~Hz}$.

- The first EGR ratio was assessed checking that fresh air mass flow rate was constant as in the reference case increasing throttle valve position. Then, the new value in spark-plug timing was set since the criteria to evaluate EGR effect on pollutants emission was to maintain the same brake torque (engine load) as in the reference case. The engine was running until TWC outlet temperature was stable before the measurement phase.

- The second and third EGR ratios were performed in the same way that the first EGR ratio.

- When the third EGR ratio had been assessed, the engine was taken to reference steady-state again, and the second reference was measured. 
In order to obtain representative results and improve their interpretation, the methodology described above was repeated for three different days. This procedure allowed data to generate results variability analysis from measurements and to obtain the mean value and deviation of each variable through the method described in Section 2.3.1.

\section{Results and discussion}

The analysis of the results has been divided in engine performance, gaseous emission and aftertreatment efficiency, and particle analysis including soot emission rate and particle number measurements.

\subsection{Engine performance analysis.}

Although the purpose of this work is not to evaluate the use of different EGR rates in terms of engine performance, some parameters such as SP timing, air mass flow rate, lambda and exhaust temperature were necessary to control in order to improve pollutant emission analysis and aftertreatment efficiency evaluation.

First of all, for each steady-state operating point, throttle valve position was adjusted as EGR rate increases (Figure 6.A) in order to maintain reference fresh air mass flow rate at the intake manifold, as Figure 6.B shows. In this sense, this modification was due to the fact that the introduction of EGR without any modification produces a strong damage to combustion process, reducing engine torque. The increase in throttle valve opening is an advantage since it implies a reduction of pumping losses and consequently an increase of mechanical efficiency at medium-load engine operating points [31]. Conversely, for full-load steady-state operating points, throttle valve position reached the maximum opening at 5\% of EGR rate, so the target of air mass flow rate was accomplished by closing the wastegate valve for $10 \%$ EGR rate.

Obviously, the addition of EGR causes a dilution effect in the charge and consequently the combustion degradation, being necessary to maintain an appropriate phasing in the SP timing in order to produce the correct combustion process and reach the same engine torque as in the reference cases, as it is shown Figure 7.A. Several authors have explored this effect, concluding that SP timing is increased as the EGR rate increases [32, 34].

The dilution effect caused by the EGR rate produces a lower combustion temperature, so the heat transfer to the cylinder walls is reduced allowing more adiabatic process [28]. This is an important issue since the reduction in combustion temperature can mitigate knock events. Although there were not measurements inside the cylinder, the reduction in temperature combustion is proved by the exhaust manifold temperature, as Figure 7.B depicts.

For medium-load, the exhaust temperature decreases as EGR rate increases for both regimes, allowing reductions around $10 \%$ of exhaust temperature. Instead, for full-load cases, the introduction of 5\% EGR rate produces an increase in exhaust temperature. Since the engine was operated with fuel enrichment at full-load conditions in order to reduce combustion temperature and reduce knock risk, the introduction of EGR rate can provide the suppression of the fuel enrichment and, consequently, an increase in the combustion temperature, as shown in Figure 7.C. For 10\% EGR rate at full-load in both regimes, the reduction in temperature combustion is depicted reaching values to the reference steady-state operating point, but without fuel enrichment in the AF mixture. 
For medium-load steady-state operating points, a reduction of BSFC is observed in Figure 7.D due to the improve in brake thermal efficiency through the reduction in combustion temperature and heat transfer losses. Furthermore, a drastically decrease in BSFC is accomplished at full-load conditions due to the suppression of fuel enrichment at 5\% EGR rate. In addition, for $10 \%$ EGR case, BSFC also continues decreasing in both regimes at full-load conditions.

\subsection{Gaseous emission and aftertreatment efficiency analysis.}

Concerning gaseous emission results, the analysis has been divided in the different compounds; i.e. raw HC, raw $\mathrm{CO}$ and raw NOx emissions. Furthermore a detailed analysis of TWC efficiency is also included.

\subsubsection{Raw HC emission.}

The specific unburned $\mathrm{HC}$ emissions versus EGR rate for the different steady-state operating points are shown in Figure 8.A.

In the case of A50 and B50 engine operating points, an increase around 61\% of raw $\mathrm{HC}$ emission was found as EGR rates increase to $15 \%$. The first reason for $\mathrm{HC}$ increasing is related to the fact that the introduction of EGR rate reduces combustion temperature and increases the quenching area [44]. The reduction generated at in-cylinder gas temperature allows a decrease in the oxidation of $\mathrm{HC}$ in the expansion and exhaust strokes. The second reason is related to the amount of unburned air/fuel mixture stored at the fire piston ring and expelled out during the exhaust stroke producing a intermediate step in the secondary $\mathrm{HC}$ oxidation reactions, which require high temperatures and available oxygen content.

However, the trend observed for unburned HC emissions are inverse for full-load cases (A100 and B100 engine points) at 5\% EGR rate. At first glance, the suppression of fuel enrichment; i.e. increasing oxygen portion in $\mathrm{AF}$, allows an increase in $\mathrm{HC}$ oxidation during the combustion process, so a reduction in unburned HC is observed. From this point, increasing EGR rate increases unburned HC emissions similarly to A50 and B50 engine operating points.

\subsubsection{Raw CO emission.}

Similarly to HC emissions, Figure 8.B shows raw carbon monoxide emission increasing as EGR amount is introduced in the engine in the case of A50 and B50 steady-state operating points. Carbon monoxide is primarily formed as the product of incomplete combustion process in the zones of combustion chamber where the air is insufficient being during the expansion and exhaust strokes where some $\mathrm{CO}$ is oxidized to form $\mathrm{CO}_{2}$ [45]. Since the introduction of EGR rate reduces the oxygen content in the mixture, it is expected an increase in $\mathrm{CO}$ formation during the combustion process as EGR does. Furthermore, as it is showed in Figure 7.B, combustion temperature is reduced when different EGR rates are applied producing a change in the $\mathrm{CO}$ to $\mathrm{CO}_{2}$ equilibrium reaction [46] avoiding $\mathrm{CO}$ oxidation and consequently increasing CO raw emission.

In the case of A100 and B100 operating points, a reduction around 90\% in both cases is depicted in Figure 8.B (varying from 131.8 to $18.54 \mathrm{mg} / \mathrm{kWh}$ and 143.4 to $13.21 \mathrm{mg} / \mathrm{kWh}$ for A100 and B100 respectively). These drastic 
reductions are due to the suppression of fuel enrichment. In the reference cases, the amount of oxygen in the AF mixture is below to the stoichiometric ratio resulting in an incomplete combustion process causing a high CO emission.

\subsubsection{Raw NOx emission.}

Focusing on raw NOx emission, on the one hand, at medium-load NOx emissions for the cases with maximum EGR ratio are reduced by about $69 \%$ (from 15.6 to $4.74 \mathrm{mg} / \mathrm{kWh}$ ) and $52 \%$ (from 13.4 to $5.6 \mathrm{mg} / \mathrm{kWh}$ ) compared to the cases without EGR at A50 and B50 engine operating points respectively, as it is shown in Figure 8.C.

The main reason for NOx reduction is due to the lower combustion temperature reached with the introduction of EGR rate, which leads to a sharp decrease of NO formation. The second reason for the NOx abatement is related with the reduction in oxygen concentration at intake manifold inlet [47]. Finally, spark-plug timing affects to NOx formation in combustion chamber and therefore, as EGR rate is increased spark-plug timing is advanced making more adiabatic the first stage of the combustion process [34]. In this sense, the NOx emissions in the cases with the maximum EGR ratio are still much lower than the baseline case (without EGR).

On the other hand, the negative aspect with the introduction of 5\% EGR rate is that NOx are increased with the stoichiometric mixture at full-load. This issue is clearly shown in Figure 8.C for both A100 and B100. Since the addition of EGR allows the suppression of the fuel enrichment and consequently the increase in combustion temperature, it leads to an increase in NO formation. However, as EGR rate increases after the suppression of the enrichment, raw NOx emissions decrease, achieving a similar value to the reference in the case of A100.

\subsubsection{Aftertreatment efficiency}

In order to provide a figure for TWC efficiency, a valve system connected to the exhaust gas analyzer was used in order to measure raw and tailpipe emissions, as it was previously explained in Section 2.2. Furthermore, the calculation method has been indicated in Equation (3) in Section 2.3.

Although there are many reactions in the catalyst for pollutants abatement, the basic operation of the aftertreatment can be simplified and based on the following reactions inside the TWC [48]:

$$
\begin{gathered}
\mathrm{C}_{x} \mathrm{H}_{y}+\frac{4 x+y}{4} \mathrm{O}_{2} \longrightarrow x \mathrm{CO}_{2}+\frac{y}{2} \mathrm{H}_{2} \mathrm{O} \\
\mathrm{CO}+\frac{1}{2} \mathrm{O}_{2} \longrightarrow \mathrm{CO}_{2} \\
2 \mathrm{NO}+2 \mathrm{CO} \longrightarrow \mathrm{N}_{2}+\mathrm{CO}_{2}
\end{gathered}
$$

Since the oxidation reactions are very affected by the oxygen content in the exhaust gas, Figure 9 shows raw $\mathrm{O}_{2}$ concentration at each steady-state operating point.

Figure 10.A1 shows the TWC efficiency for HC emission calculated according to HC tailpipe emission showed in Figure 10.A2. In this way, for cases A50 and B50 a reduction in the oxidation efficiency is depicted in both case. 
Since the principal reaction for $\mathrm{HC}$ abatement is based in the oxidation through $\mathrm{O}_{2}$ presence in the exhaust gas, as it is shown in the reaction of Equation 10, a reduction in the TWC efficiency for HC emission is observed due to the increase in raw $\mathrm{HC}$ emission and a slightly decrease in $\mathrm{O}_{2}$ content, as Figure 9 previously showed. However, the TWC efficiency is always above $97 \%$, which are the values when the aftertreatment is working correctly.

In the case of A100 or B100 steady-state operating points, $\mathrm{HC}$ oxidation efficiency is around $60 \%$ for reference cases. It is due to the fact that fuel enrichment drastically reduces the $\mathrm{O}_{2}$ presence in the raw exhaust gas. In this regard, the oxidation reaction does not take place inside the TWC. However, when EGR rate is introduced, fuel enrichment is suppressed and the oxygen content increases, recovering values for HC efficiency around $95 \%$.

Focusing on CO efficiency, a slightly decrease in this efficiency is observed for A50 and B50 cases. The reduction in the oxidation efficiency for this compound is also related to the oxygen content, as the reaction of Equation 11 represents. Anyway, CO efficiency is always higher than 99\%, as it is shown in Figure 10.B1. Similar to HC efficiency for A100 and B100 reference cases, the fuel enrichment causes a reduction in CO efficiency, showing values around $20 \%$. As EGR rate is introduced, CO efficiency recovers values around $95 \%$ since overfueling is avoided providing low level tailpipe $\mathrm{CO}$ emissions, as Figure 10.B2 represents.

Finally, when TWC efficiency is analyzed by means of NOx emission, a global trend showing a reduction in NOx abatement is depicted for all cases in Figure 10.C1. Since the reduction reaction given in Equation 12 is highly dependent of CO content in the exhaust gas [49], the reduction in this pollutant could help to inhibit the reactions of NOx reduction, and consequently decreasing TWC NOx efficiency and increasing tailpipe emissions as Figure 10.C2 shows.

\subsection{Soot emission analysis.}

In this part of the results, soot mass emission is analyzed in order to quantify the evolution of particle matter when different EGR rates are assessed in four different steady-state operation points.

Figure 11 shows the specific tailpipe soot mass emission for each operating mode. As it is observed, a reduction trend is depicted for all cases. On the one hand, a maximum reduction of 58\% is observed for A100 case varying from 1.92 to $0.79 \mathrm{mg} / \mathrm{kWh}$. On the other hand, the minimum reduction is depicted for B50 case, which shows a reduction about $34 \%$ (from 1.21 to $0.81 \mathrm{mg} / \mathrm{kWh}$ ).

It is necessary to state how soot particles are formed inside the cylinder during the combustion process due to the fact that the EGR addition has strong effects on combustion process.

It is well known that soot is mainly carbon originated from high combustion temperature and it is produced as an intermediate step between the fuel evaporation and fuel dehydrogenation. The evolution of molecules from vapor-phase or liquid-phase to solid soot particles includes phenomena such as pyrolysis, precursor formation, polymerization, nucleation and surface growing [50], as shown in Figure 12.

Firstly, fuel suffers the pyrolysis phenomenon due to high temperatures in the combustion chamber, whereby its molecular structure is altered and partially oxidized. Haynes and Wagner determined that $\mathrm{C}_{2} \mathrm{H}_{2}, \mathrm{C}_{2} \mathrm{H}_{4}, \mathrm{CH}_{4}$ were 
typical compounds originated from fuel pyrolysis [51]. From this point, aromatic ring formation is due to the attack of $\mathrm{C}_{2} \mathrm{H}_{2}$ to $\mathrm{n}-\mathrm{C}_{4} \mathrm{H}_{3}$ radicals (at high temperatures) or $\mathrm{n}-\mathrm{C}_{4} \mathrm{H}_{5}$ radicals (at low temperatures). The first ring changes by $H A C A$ process (Hydrogen abstraction-acetylene addition). HACA mechanism is considered as a polymerization process due to the fast velocity involved, and two phases can be identified: hydrogen is released first, which activates the aromatic molecules, followed by the addition of acetylene, which promotes molecular growth and cyclization of polycyclic aromatic hydrocarbons (PAH).

Experimental studies show that the transition between precursor-soot occurs at 500 to $2000 \mathrm{Da}$. On one hand, due to the high supersaturation of macromolecular precursors, the partial pressure of these precursors acts as a driving force, so that the macromolecules physically condense to yield in a soot liquid phase. On the other hand, there is a theory that states that PAH molecules grow until they have a solid transition [52].

In the final stage of soot formation, surface growth is a predominant process which occurs by the addition of mass on the nucleate soot particle surface and leads to an increase in the soot mass, but not in the particle number. During surface growing, active reactants portion of primary soot particle accepts the gas-phase of acetylene hydrocarbons. This mechanism (for surface growing) continues when the primary particles are moved to less active cold areas, where the hydrocarbons concentration is less than the limit of soot inception rate [53].

Hence, considering what has been stated above, the first step for soot formation is based on the dehydrogenation of $\mathrm{HC}$ being this mechanism highly dependent on the temperature. Since EGR addition allows a reduction in combustion temperature and increase in unburned $\mathrm{HC}$, nuclei-precursor formation is reduced and consequently inhibit the surface growing and coagulation mechanisms. This causes a general soot reduction trend when EGR rate is added.

\subsection{Particle analysis.}

Particle emission is analyzed measuring PSD and separating both nucleation-mode and accumulation-mode for each steady-state operating point including different EGR rates.

Figure 13 shows PSDs for each steady-state analyzed. As it is shown in the medium-load cases, PSDs present a bimodal shape with peaks at 10 and $50 \mathrm{~nm}$ where both modes are comparable (i.e. accumulation-mode and nucleationmode particle concentrations).

As it is shown in Figure 13, the increase in EGR rate produces a decrease in the mode of the distribution (particle diameter which presents the higher particle concentration) and a decrease in particle concentration. These results point out that the production of different EGR rates can decrease particle concentration. This phenomenon is opposite to the effect of EGR rate in diesel engines where the addition of EGR rate increases particle emission. In this engine, the homogeneous mixture in combustion chamber is burned by flame propagation, which is different to the diffusion flame in diesel engines [54].

In order to provide a better understanding of the effect of EGR rate on particle size distribution, Figure 14 shows the calculated GMD for each operating point. This value points out the overall value of PSD taking into account both particle concentration for each diameter and total particle concentration. As it can be seen, the reduction in all GMDs 
imply a strongly particle concentration reduction for large particle diameters (accumulation-mode particles), but just without affecting smaller diameters when EGR is introduced in medium load operating points.

However, since nucleation-mode particles for A100 case is higher than accumulation-mode particles, the introduction of EGR cause a reduction in both modes being slightly higher the reduction in nucleation-mode which causes a slightly increase in GMD as EGR rate is increased. For B100 engine operating point, the reduction in particle concentration is accomplished in both modes, showing similar shape and similar peaks concentration in both modes as EGR is included. Thus, it implies a flat trend in GMD, as Figure 14 shows.

Finally, Figure 15 shows particle composition analysis separating nucleation-mode, accumulation-mode and total particles emitted. The percentages of variation respect to the reference case as EGR rate is increased are also included for each steady-state operating point.

Figure 15.A and Figure 15.B show that the accumulation-mode particle concentration is higher than nucleationmode particle concentration in the operating points A50 and B50 being similar results as reported Bonatesa et al. [55]. A slight reduction in nucleation-mode particle emission and progressively reduction in accumulation-mode particle emission is depicted when EGR rate is increased. The reduction in nucleation-mode particle emission produces a reduction in the coagulation of nuclei which is translated to a reduction in the accumulation-mode particle emission. Since there is a lower nucleation-mode particle concentration, accumulation-mode particles are reduced due to the reduction in surface growing mechanism since there are not exist certain particles on which to grow (nucleationmode). Obviously, if nucleation-mode and accumulation-mode particles are reduced, total particle concentration is reduced. In this sense, the reduction in accumulation-mode particle concentration is higher than nucleation-mode, so as previously Figure 14 shows, the GMDs decrease.

Contrarily to A50 and B50 cases, for A100 and B100 operating points, nucleation-mode particle emission is above than accumulation-mode particle emission as Figure 15.C and Figure 15.D shown. At first glance, the suppression of fuel enrichment and addition of EGR cause a reduction in both nucleation-mode and accumulation-mode particle concentration for 5\% EGR rate. When variation plots are observed in detail, a further reduction in nucleation-mode particle emission is found progressively, producing a higher reduction in accumulation-mode particle emission than in medium-load cases.

\section{Conclusions}

The objective of this work has been to investigate the effect on pollutant emission and TWC efficiency related to the use of cooled LP-EGR system in a turbocharged direct-injection gasoline engine which complies with EURO5 standards.

The experiments performed in this work have been carried out considering different EGR ratios at four different steady-state operating points. The original engine calibration is considered as a reference being compared with the different results as EGR rate is increased for each operating point. After present the most relevant conclusions on 
engine performance and main results of raw gaseous emission and TWC efficiency, tailpipe soot emission, particle size distribution and geometric mean diameter conclusions have been highlighted.

Considering the engine performance, the main results found during this study were:

- As EGR rate is increased in A50 and B50 cases, throttle valve position is progressively opened in order to maintain fresh air mass flow rate, so a reduction in pumping losses is expected.

- EGR acts a diluent gas, so spark-plug timings were advanced for maintaining engine brake torque. It produces a better combustion phasing reducing peak combustion temperature which involves a reduction on exhaust gas temperature.

- At full-load steady-state operating points, EGR is used to eliminate fuel enrichment in the AF mixture $(\lambda<1)$ providing a drastically reduction in BSFC.

- The reduction in heat transfer combustion temperature and pumping losses at part-load steady-state operating points leads in an reduction of BSFC.

Focusing on raw gaseous emission and aftertreatment device efficiency, these conclusions have been obtained through this study:

- A global trend showing an increase in raw HC emission is depicted as EGR is introduced for all steady-state operating points due to the reduction in combustion temperature and the increase in quenching area.

- Raw CO emissions slightly increase at part-load when EGR rate is increased due to the reduction in oxygen content in $\mathrm{AF}$ mixture and combustion temperature, which promotes a change in the $\mathrm{CO}$ to $\mathrm{CO}_{2}$ equilibrium reaction.

- However, a drastically reduction around $90 \%$ in raw CO emissions is concluded at full-load steady-state operating points. Since the introduction of EGR can avoid the fuel enrichment, $\mathrm{CO}$ formation is reduced.

- NOx formation is highly dependent of combustion temperature, so the reduction in combustion temperatures as EGR is included implies a decrease about $50 \%$ of raw NOx emission for part-load steady-state.

- An increase in NOx formation at full-load was observed when 5\% EGR is introduced due to the fact that the suppression of fuel enrichment produces an increase in combustion temperature. Thus NOx formation is increased. However, as EGR rate increasing, raw NOx emission decreases up to similar values to the reference case at high EGR rates.

- A global reduction in the TWC efficiency for all compounds was found when EGR is included. On the one hand, concerning oxidation reactions (involving $\mathrm{CO}$ and $\mathrm{HC}$ ), a reduction in both $\mathrm{raw}_{2}$ and exhaust temperature lies in a decrease in the oxidation efficiency. On the other hand, reduction reaction (involving NOx) is highly 
dependent of $\mathrm{CO}$ content in the exhaust gas, so the reduction of this pollutant could help to inhibit the reactions of NOx reduction, and consequently decreasing TWC NOx efficiency.

- Instead, for full-load cases, the fuel enrichment suppression implies a correctly TWC performance, so an increase in oxidation rates was observed as EGR is included.

Finally, the main conclusions reached concerning particle emission are listed below:

- Soot emission is reduced as EGR is included for all cases tested.

- Nucleation-mode particle emission proportion is higher for medium-load than at full-load cases.

- PSDs mode is displaced to smaller diameters and accumulation-mode particle concentration decreases with the increase of EGR rate for medium-load cases which produces a reduction of GMD.

- For full-load operating points, a general reduction trend in particle concentration is found through the introduction of EGR.

Despite the results obtained, it is noticeable the importance of EGR systems design in order to reduce NOx emission and combustion temperature when it is added to a GTDi engine. The introduction of this system contrarily lies to an increase in $\mathrm{CO}$ and $\mathrm{HC}$ emission suggesting the improvement in combustion chamber design and injector placement in order to reduce pool fires or imperfect mixing and improve these emissions. In global terms, looking to the past and present pollutants emission normative, the reduction in NOx has been more pronounced than the CO and HC along years, so EGR system appears as a good solution to improve gaseous emission. Furthermore, focusing on future particle emission normative (soot and PN), there is a reduction on both with this system. In this sense, lower oxidation rate of EGR-combustion soot due to internal burning in the engine cylinder possibly is another reason for its low PN and soot emissions, which requires further investigation. Furthermore, future GTDi engines will incorporate gasoline particle filters (GPF) in order to comply future normative (PN Euro 6 limit: $6 \cdot 10^{11}$ \#/ $\mathrm{km}$ ), so these results show some benefits due to the fact that lower particle emission could result in a reduction of accumulated soot inside the filters, allowing a reduction in exhaust backpressure and generating fuel savings by extending lifetime between active regenerations of GPF.

\section{Acknowledgements}

The equipment used in this work has been partially supported by FEDER project funds "Dotación de infraestructuras científico técnicas para el Centro Integral de Mejora Energética y Medioambiental de Sistemas de Transporte (CiMeT), (FEDER- ICTS-2012-06)", framed in the operational program of singular scientific and technical infrastructure of the Ministry of Science and Innovation of Spain. 


\section{References}

[1] 2008/692/EC, Implementing and amending REGULATION (EC) N.715/2007 OF THE EUROPEAN PARLIAMENT AND OF THE COUNCIL of 20 June 2007 on type-approval of motor vehicles with respect to emissions from light passenger and commercial vehicles (EURO 5 and EURO 6) and on access to vehicle repair and maintenance information.

[2] Peckham MS, Finch A, Campbell B, Analysis of transient $\mathrm{HC}$, $\mathrm{CO}$, $\mathrm{NOx}$ and $\mathrm{CO}_{2}$ emissions from GDi engine using fast response gas analyzers, in: SAE Technical Paper 2011-01-1227.

[3] Alkidas AC, Combustion advancements in gasoline engines, Energ Convers Manage 48 (2007) 2751-2761.

[4] Lake T, Stokes J, Murphy R, Osborne R, Schamel A, Turbocharging concepts for downsized Di gasoline engines, in: SAE Technical Paper 2004-01-0036.

[5] Gao Z, Curran SJ, Parks II JE, Smith DE, Wagner RM, Daw CS, Edwards KD, Thomas JF, Drive cycle simulation of high efficiency combustions on fuel economy and exhaust properties in light-duty vehicles. Appl Energ (2015), http://dx.doi.org/10.1016/j.apenergy.2015.03.070.

[6] Stiebels B, Schweizer M, Ebus F, Pott E, Die FSI-Technologie von Volkswagen - nicht nu rein Verbrauchskonzept. In: Direkteinspritzung im Ottomotor IV. Expert-Verlag, 2003

[7] Nafaji G, Ghobadian B, Tavakoli T, Buttsworth D, Yusaf T, Faizollahnejad M, Performance and exhaust emissions of a gasoline engine with ethanol blended gasoline fuels using artificial neural network, Appl Energ 86(5) (2009) 630-639.

[8] Wang C, Xu H, Herreros JM, Wang J, Cracknell R, Impact of fuel and injection system on particle emissions from a GDI engine, Appl Energ 132 (2014) 178-191.

[9] Maricq MM, Szente JJ, Jahr K, The impact of ethanol fuel blends on PM emission from a light-duty GDi vehicle, Aerosol Sci Tech 46 (2012) $576-583$

[10] Pope C, Dockery D, Health effects of fine particulate air pollution: lines that connect, J Air Waste Manage 56 (2006) 709-742.

[11] Davidson CI, Phalen RF, Solomon PA, Airborne particulate matter and human health: a review, Aerosol Sci Technol 39(1) (2005) 62-78.

[12] Giechaskiel B, Dilara P, Sandbach E, Andersson J, Particle Measurement Program (PMP) light-duty inter-laboratory exercise: comparison of different particle number measurement systems, Meas Sci Technol 19 (2008) 095401.

[13] Fontana G, Galloni E, Experimental analysis of a spark-ignition engine using exhaust gas recycle at wot operation, Appl Energ 87 (2010) $2187-2193$

[14] Merola SS, Vaglieco BM, Knock investigation by flame and radical species detection in spark ignition engine for different fuels, Energ Convers Manage 48 (2007) 2897-2910.

[15] Agarwal D, Singh SK, Agarwal AK, Effect of exhaust gas recirculation (EGR) on performance, emission, deposits, and durability of a constant speed compression ignition engine, Appl Energ 88 (2011) 2900-2907.

[16] Gradin B, Angstrom HE, Replacing fuel enrichment in a turbocharged SI engine: lean burn or cooled EGR, in: SAE Technical Paper 199901-3505.

[17] Fathi M, Saray RK, Checkel MD, The influence of exhaust gas recirculation (EGR) on combustion and emission of n-heptane/natural gas fueled homogeneous charge compression ignition (HCCI) engines, Appl Energ 87 (2011) 4719-4724.

[18] Bai YL, Wang Z, Wang JX, Part-load characteristics of direct injection spark ignition engine using exhaust gas trap, Appl Energ 87 (2010) 2640-2646.

[19] Potteau S, Lutz P, Leroux S, Stephanie M, Cooled EGR for a turbo SI engine to reduce knocking and fuel consumption, in: SAE Technical Paper 2007-01-3978.

[20] Bermúdez V, Luján JM, Pla B, Linares WG, Effects of low pressure exhaust gas recirculation on regulated and unregulated gaseous emissions during NEDC in a light-duty diesel engine, Energy 36(1) (2011) 5655-5665.

[21] Fontana G, Galloni E, Variable valve timing for fuel economy improvement in a small spark-ignition engine, Appl Energ 86 (2009) 96-105.

[22] Blank H, Dismon H, Kochs MW, Sanders M, EGR and air management for direct injection gasoline engines, in: SAE Technical Paper 2002-01-0707. 
[23] Kaiser M, Krueger U, Harris R, Cruff L, Doing more with less - the fuel economy benefits of cooled EGR on a direct injected spark ignition boosted engine, in: SAE Technical Paper 2010-01-0589.

[24] Sarikoc F, Kettner A, Velji M, Spicher U, Potential of reducing the NOx emission in a spray guided Di gasoline engine by stratified exhaust gas recirculation (EGR), in: SAE Technical Paper 2006-01-1261.

[25] Diana S, Giglio V, Iorio B, Police G, A strategy to improve the efficiency of stoichiometric spark ignition engines, in: SAE Technical Paper 961953.

[26] Tomazic D, Pfeifer A, Cooled EGR - a must or an option for 2002/04, in: SAE Technical Paper 2002-01-0962.

[27] Haiqiao W, Tianyu Z, Gequn S, Linlin T, Yuesen W, Gasoline engine exhaust gas recirculation - a review, Appl Energ 99 (2012) $534-5444$.

[28] Zhijin Z, Tianyou W, Ming J, Qun W, Xiangzan M, Gequn S, Combustion and particle number emissions of a direct injection spark ignition engine operating on ethanol/gasoline and n-butanol/gasoline blends with exhaust gas recirculation, Fuel 130 (0) (2014) $177-188$.

[29] Alger T, Gingrich J, Khalek IA, Mangold B, The role of EGR in PM emissions from gasoline engines, in: SAE Technical Paper 2010-01-0353.

[30] Liang B, Ge Y, Tan J, Han X, Liping G, Hao L, Ye W, Dai P, Comparison of PM emission from a gasoline direct injected (GDi) vehicle and port fuel injected (PFI) vehicle measured by electrical low pressure impact (ELPI) with two fuels: Gasoline and M15 methanol gasoline, J Aerosol Sci 57 (2013) 22-31.

[31] Zhijin Z, Haiyan Z, Tianyou W, Ming J, Effects of tumble combined with EGR (exhaust gas recirculation) on the combustion and emissions in a spark ignition engine at part loads, Energy 65 (2014) 18-24.

[32] Galloni E, Fontana G, Palmaccio R, Effects of exhaust gas recycle in a downsized gasoline engine, Appl Energ 105 (2013) 99-107.

[33] Roth D, Keller P, Becker M, Requirements of external EGR systems for dual cam phase turbo GDi engines, in: SAE Technical Paper 2010-01-0588.

[34] Gu X, Huang Z, Cai J, Gong J, Wu X, Lee C, Emission characteristics of a spark-ignition engine fuelled with gasoline-n-butanol blends in combination with EGR, Fuel 93 (2012) 611-617.

[35] Johnson T, Caldow R, Pocher A, Mirme A, Kittelson D, An engine exhaust particle sizer spectrometer for transient emission particle measurements, in: SAE Technical Paper 2004-01-1341.

[36] Desantes JM, Bermúdez V, Molina S, Linares WG, Methodology for measuring exhaust aerosol size distributions using an engine test under transient operating conditions, Meas Sci Technol 22 (2011) 115101.

[37] Montajir RM, Kusaka T, Bamba Y, Adachi M, A new concept for real-time measurement of particulate matter (Soot and SOF), in: SAE Technical Paper 2005-01-3605.

[38] Bermúdez V, Pastor JV, López JJ, Campos D, Experimental correlations for transient soot measurement in diesel exhaust aerosol with light extinction, electrical mobility and diffusion charger sensor techniques, Meas Sci Technol 25 (2014) 065204.

[39] Seinfeld JH, Pandis SN, Atmospheric Chemistry and Physics: From Air Pollution to Climate Change, 2nd Edition, John Wiley \& Sons Inc., Hoboken, New Jersey, 2006.

[40] Lapuerta M, Armas O, Gómez A, Diesel particle size distribution estimation from digital image analysis, Aerosol Sci Tech 37(4) (2003) 369-381.

[41] Sarikoc F, Kettner M, Velji A, Spicher U, Krause A, Elsaesser A, Potential of reducing the NOx emissions in a spray guided DI gasoline engine by stratified exhaust gas recirculation (EGR), in: SAE Technical Paper 2006-01-1261.

[42] Stiebels B, Schweizer M, Ebus F, Pott E, Die FSI-Technologie von Volkswagen nicht nu rein Verbrauchskonzept. In: Direkteinspritzung im Ottomotor IV. Expert-Verlag, 2003.

[43] Waltner A, Luckert P, Schaupp U, Rau E, Kemmler R, Weller R, Die J, Zukunftstechnologie des Ottomotors: strahlgefuehrte Direkteinspritzung mit Piezo-Injektor, 27, Internationales Wiener Motorensymposium, Fortschrittberichte VDI, Reihe 12, Nr.622, Dusseldorf: VDI Verlag, 2006.

[44] Spicher U, Kubach H, Haentsche JP, Die strahlgefuehrten direkteinspritzung als zukunfts-konzept fuer ottomotoren, MTZ-Konferenz Motor (2006) Stuttgart. 


\section{Nomenclature}

Abbreviations

$\mathrm{AF}$

BSFC

BTE

$\mathrm{CO}$

CI

$\mathrm{CO}_{2}$

$\mathrm{COV}$

ED

EGR

EEPS

FPS

GTDi

GMD
Air-to-fuel

Brake specific fuel consumption

Brake thermal efficiency

Carbon monoxide

Compression ignition

Carbon dioxide

Coefficient of variation

Diffusion charging sensor

Direct injection

Engine control unit

Ejector diluter

Exhaust gas recirculation

Engine exhaust particle sizer

Fine particle sampler

Gasoline turbocharged direct-injection

Geometric mean diameter 


$\begin{array}{ll}\text { GPF } & \text { Gasoline particle filter } \\ \text { HC } & \text { Hydrocarbons } \\ \text { IC } & \text { Internal combustion } \\ \text { LP-EGR } & \text { Low pressure exhaust gas recirculation } \\ \text { NOx } & \text { Nitrogen oxides } \\ \text { PFI } & \text { Port fuel injection } \\ \text { PM } & \text { Particle matter } \\ \text { PN } & \text { Particle number } \\ \text { PSD } & \text { Particle size distribution } \\ \text { PTD } & \text { Porous tube diluter } \\ \text { RON } & \text { Research octane number } \\ \text { SI } & \text { Spark ignition } \\ \text { SP } & \text { Spark-plug timing } \\ \text { SOI } & \text { Start of injection } \\ \text { TMV } & \text { Total mean value } \\ \text { TWC } & \text { Three way catalyst } \\ & \end{array}$

\section{List of Tables}

- Table 1.- GTDi engine main characteristics..

- Table 2.- Gasoline properties.

- Table 3.- Characteristics of engine instrumentation.

- Table 4.- Characteristics of pollutant equipment.

- Table 5.- Steady-state operating points. Main parameters.

\section{List of Figures}

- Figure 1.- Cylinder head and piston geometries.

- Figure 2.- Experimental set-up for LP-EGR system evaluation in a GTDi engine.

- Figure 3.- Particle evolution at dilution system. Theoretical phase-diagram used in the methodology for measuring particle size distribution [36].

- Figure 4.- Lambda engine map point. Steady-state operating point selected.

- Figure 5.- Methodology employed for testing each EGR ratio at different steady-state operating points.

- Figure 6.- Throttle valve position and fresh air mass flow rate as function of EGR rate at each steady-state operating point.

- Figure 7.- Engine performance at different EGR rate at each steady-state operating points. A) Spark-plug timing. B) Exhaust manifold temperature. C) Lambda. D) BSFC. 
- Figure 8.- Raw gaseous emission for different EGR rate at each steady-state operating points. A) Raw HC emission. B) Raw CO emission. C) Raw NOx emission.

- Figure 9.- Oxygen content in the exhaust gas upstream the TWC.

- Figure 10.- Three way catalyst (TWC) efficiency and tailpipe emissions for different EGR rate at each steady-state operating points. A1) HC efficiency. A2) HC tailpipe emission. B1) CO efficiency. B2) CO tailpipe emission. C1) NOx efficiency. C2) NOx tailpipe emission.

- Figure 11.- Tailpipe soot emission for different EGR rates at each steady-state operating points.

- Figure 12.- Sketch of soot formation.

- Figure 13.- Tailpipe particle size distribution (PSD) for different EGR rates at each steady-state operating points. A) PSD at 2000 rpm medium-load. B) PSD at 3000 rpm medium-load. C) PSD at $2000 \mathrm{rpm}$ full-load. D) PSD at $3000 \mathrm{rpm}$ full-load.

- Figure 14.- Tailpipe geometric mean diameter (GMD) for different EGR rates at each steady-state operating points.

- Figure 15.- Tailpipe particle composition analysis for different EGR rate at each steady-state operating points. A) Particle composition at 2000 rpm medium-load. B) Particle composition at 3000 rpm medium-load. C) Particle composition at 2000 rpm full-load. D) Particle composition at 3000 rpm full-load. 
Table 1: GTDi engine main characteristics.

\begin{tabular}{lcc}
\hline \hline Characteristic & Unit & Value \\
\hline Type & {$[-]$} & 4 -cycle \\
Valves by cilinder & {$[-]$} & 4 \\
Number of cylinders & {$[-]$} & 4 \\
Compression ratio & {$[-]$} & $10.2: 1$ \\
Diameter & {$[\mathrm{mm}]$} & 87 \\
Stroke & {$[\mathrm{mm}]$} & 83 \\
Maximun power & {$[\mathrm{kW}]$} & 153 at $6000 \mathrm{~min}^{-1}$ \\
Maximun torque & {$[\mathrm{Nm}]$} & 300 at $2000 \mathrm{~min}^{-1}$ \\
\hline \hline
\end{tabular}

Table 2: Gasoline properties.

\begin{tabular}{lcc}
\hline \hline Property & Unit & Value \\
\hline RON & {$[-]$} & 98.0 \\
Density at $15^{\circ} \mathrm{C}$ & {$\left[\mathrm{kg} / \mathrm{m}^{3}\right]$} & 735.7 \\
Lower heating value & {$[\mathrm{MJ} / \mathrm{kg}]$} & 44.09 \\
Sulfur content & {$[\mathrm{ppm}]$} & 7.3 \\
Oxygen & {$[\mathrm{wt} \%]$} & 2 \\
Aromatic & {$[\mathrm{Vol} \%]$} & 22.9 \\
Benzene & {$[\mathrm{Vol} \%]$} & 0.68 \\
Distilation $\mathrm{T}_{10 \% \text { Vol. }}$ & {$\left[{ }^{\circ} \mathrm{C}\right]$} & 51.3 \\
Distilation $\mathrm{T}_{50 \%} \mathrm{Vol}$. & {$\left[{ }^{\circ} \mathrm{C}\right]$} & 85.8 \\
Distilation $\mathrm{T}_{90 \%}$ Vol. & {$\left[{ }^{\circ} \mathrm{C}\right]$} & 142.9 \\
\hline \hline
\end{tabular}

Table 3: Characteristics of engine instrumentation.

\begin{tabular}{lccc}
\hline \hline Magnitude & Sensor/Instrument & Range & Error \\
\hline Temperature & Thermocouple Type K & $-200-1,200\left({ }^{\circ} \mathrm{C}\right)$ & $\pm 1.1^{\circ} \mathrm{C}$ or $0.4 \%$ (actual value) \\
Mean pressure & Piezoresistive PMA P40 & $0-6(\mathrm{bar})$ & $\pm 0.3 \%$ (full scale) \\
Fuel mass flow & Gravimetric balance & $0-27(\mathrm{~kg} / \mathrm{h})$ & $\pm 0.12 \%$ (full scale) \\
Air mass flow & Sensyflow ABB FMT700-P & $0-720(\mathrm{~kg} / \mathrm{h})$ & $\pm 1 \%$ (actual value) \\
Torque & Torquimeter & $-650-650(\mathrm{Nm})$ & $\pm 0.1 \%$ (full scale) \\
\hline \hline
\end{tabular}


Table 4: Characteristics of pollutant equipment.

\begin{tabular}{|c|c|c|c|}
\hline Magnitude & Instrument & Range & Sensitivity \\
\hline THC & HFID & $0-5000(\mathrm{ppm})$ & $\pm 1 \%$ (full scale) \\
\hline NO/NOx & CLD & $0-10000(\mathrm{ppm})$ & $\pm 1 \%$ (full scale) \\
\hline $\mathrm{CO}_{2}$ & NDIR & $0-20(\% \mathrm{Vol})$ & $\pm 1 \%$ (full scale) \\
\hline $\mathrm{CO}_{\mathrm{L}}$ & NDIR & $0-5000(\mathrm{ppm})$ & $\pm 1 \%$ (full scale) \\
\hline $\mathrm{CO}_{\mathrm{H}}$ & NDIR & $0-12(\% \mathrm{Vol})$ & $\pm 1 \%$ (full scale) \\
\hline $\mathrm{O}_{2}$ & MPA & $0-25(\% \mathrm{Vol})$ & $\pm 1 \%$ (full scale) \\
\hline Particle conc. (Dn) & TSI-EEPS & $\exp [-1.024 \cdot \ln (D n)+7.241]-\exp [-0.989 \cdot \ln (D n)+17.824] \quad\left(\# / \mathrm{cm}^{3}\right)$ & $\pm 5 \%$ (actual value) \\
\hline Soot conc. & TSI-DCS100 & $0-150\left(\mathrm{mg} / \mathrm{m}^{3}\right)$ & $\pm 0.5 \%$ (full scale) \\
\hline
\end{tabular}

Table 5: Steady state operating points. Main parameters.

\begin{tabular}{|c|c|c|c|c|c|}
\hline Point & Speed & Torque & EGR rate & SP & SOI \\
\hline & {$[\mathrm{rpm}]$} & [N.m] & {$[\%]$} & {$\left[{ }^{\circ} \mathrm{BTDC}\right]$} & [ $\left.{ }^{\mathrm{o}} \mathrm{BTDC}\right]$ \\
\hline $\mathrm{A} 50_{\text {ref }}$ & 2000 & 165 & 0 & 17.1 & 279.5 \\
\hline $\mathrm{A} 50_{5} \% \mathrm{EGR}$ & 2000 & 165 & 5 & 20.25 & 279.5 \\
\hline $\mathrm{A} 50_{10 \% \mathrm{EGR}}$ & 2000 & 166 & 10 & 25.5 & 279.5 \\
\hline $\mathrm{A} 50_{15 \% \mathrm{EGR}}$ & 2000 & 167 & 15 & 30 & 279.5 \\
\hline $\mathrm{A} 100_{\mathrm{ref}}$ & 2000 & 279 & 0 & 5.25 & 299.5 \\
\hline $\mathrm{A} 100_{5 \% \mathrm{EGR}}$ & 2000 & 289 & 5 & 8.85 & 299.5 \\
\hline $\mathrm{A} 100_{10 \% \mathrm{EGR}}$ & 2000 & 282 & 10 & 13.25 & 299.5 \\
\hline $\mathrm{A} 100_{15 \% \mathrm{EGR}}$ & 2000 & 282 & 15 & 17.25 & 299.5 \\
\hline B50 ref & 3000 & 159 & 0 & 21 & 290.25 \\
\hline $\mathrm{B} 50_{5 \% \mathrm{EGR}}$ & 3000 & 162 & 5 & 22.5 & 290.25 \\
\hline $\mathrm{B} 50_{10 \% \mathrm{EGR}}$ & 3000 & 164 & 10 & 29.5 & 290.25 \\
\hline B50 $15 \%$ EGR & 3000 & 165 & 15 & 36 & 290.25 \\
\hline $\mathrm{B} 100_{\text {ref }}$ & 3000 & 290 & 0 & 13.5 & 310.25 \\
\hline $\mathrm{B} 100_{5} \% \mathrm{EGR}$ & 3000 & 292 & 5 & 18 & 310.25 \\
\hline B $100_{10 \% \mathrm{EGR}}$ & 3000 & 288 & 10 & 22.5 & 310.25 \\
\hline
\end{tabular}

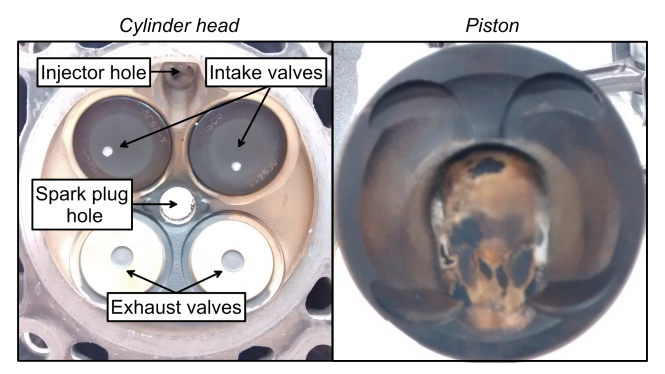

Figure 1: Cylinder head and piston geometries. 


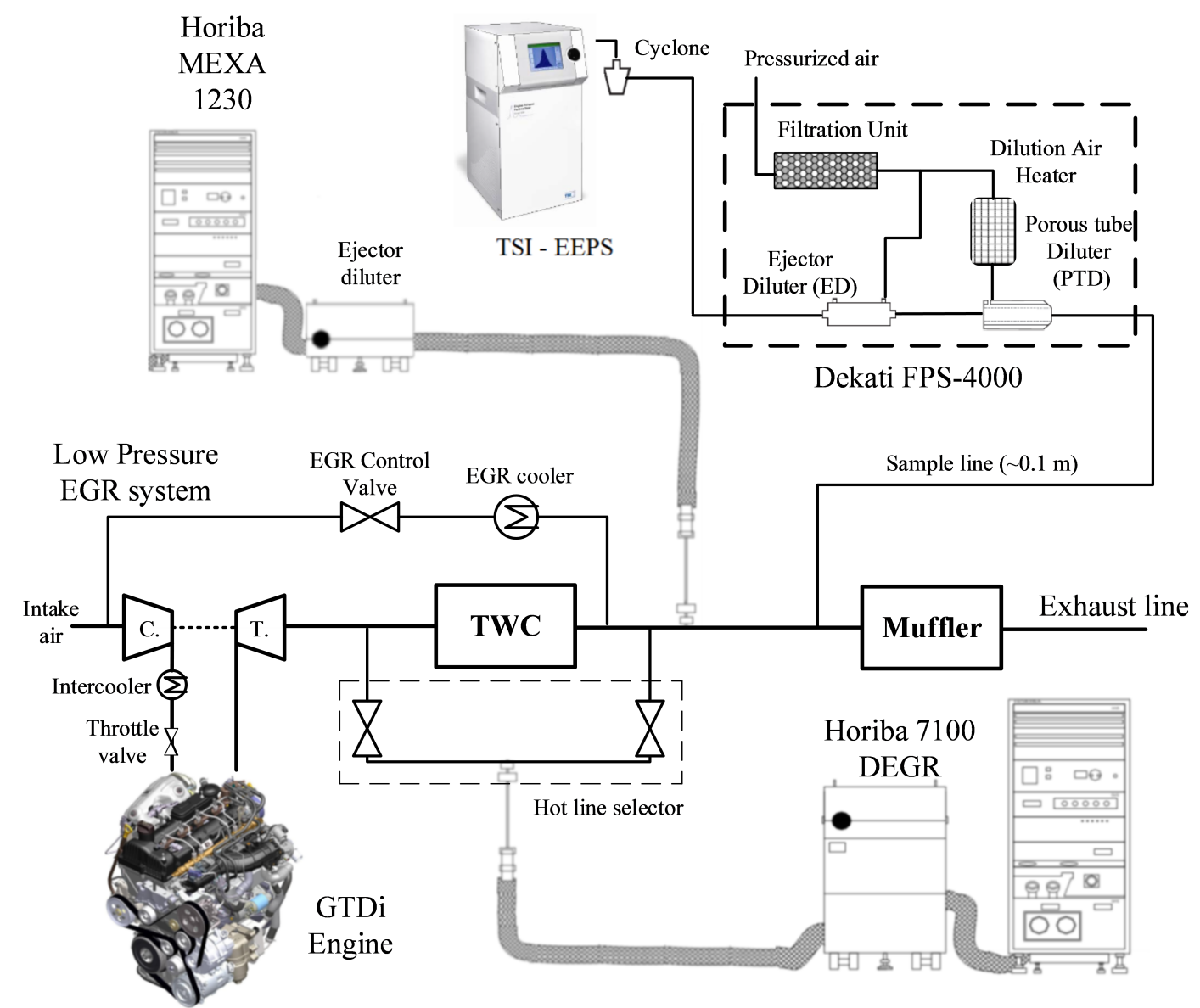

Figure 2: Experimental set-up for LP-EGR system evaluation in a GTDi engine.

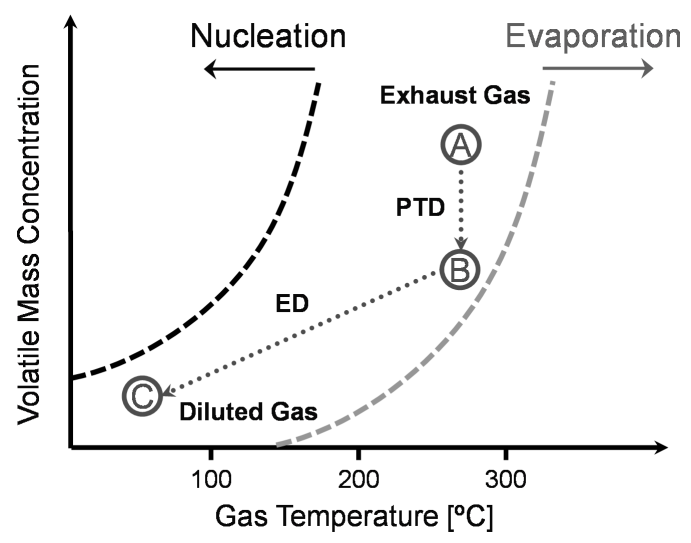

Figure 3: Particle evolution at dilution system. Theoretical phase-diagram used in the methodology for measuring particle size distribution [36]. 


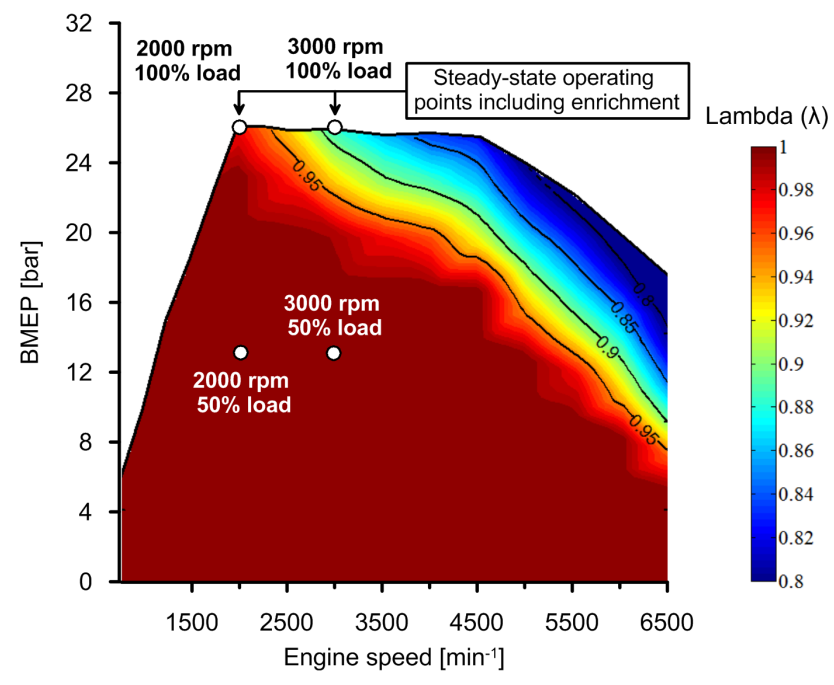

Figure 4: Lambda engine map point. Steady-state operating point selected.

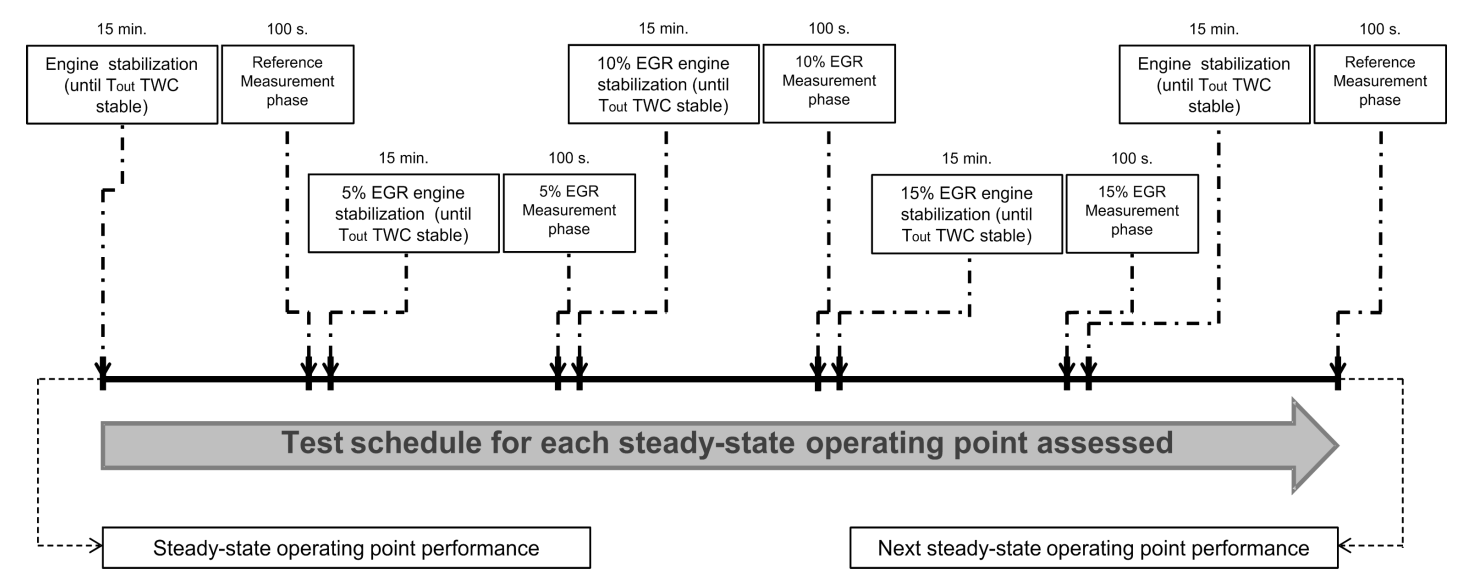

Figure 5: Methodology employed for testing each EGR ratio at different steady-state operating points. 


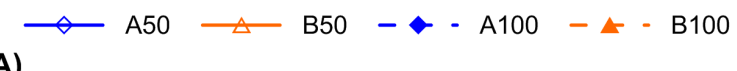

A)
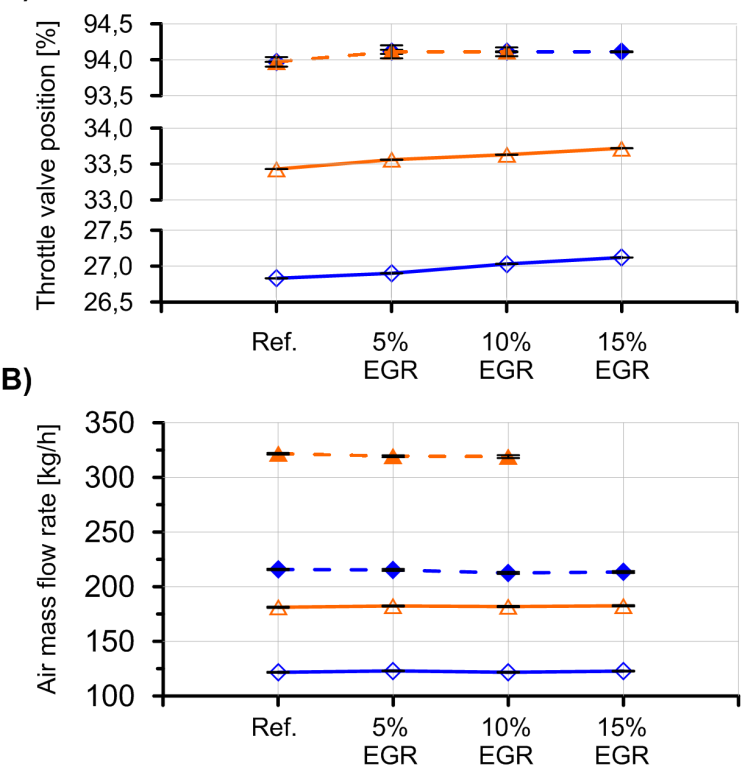

Figure 6: Throttle valve position and fresh air mass flow rate as function of EGR rate at each steady-state operating point. 


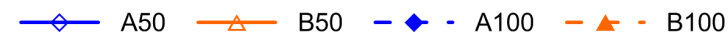

A)

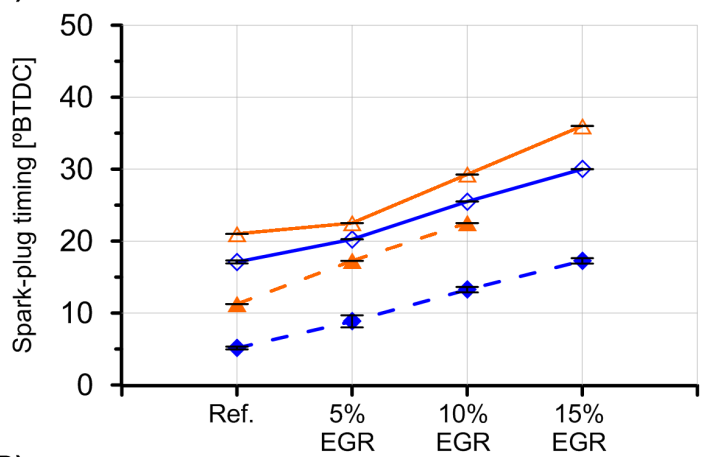

B)

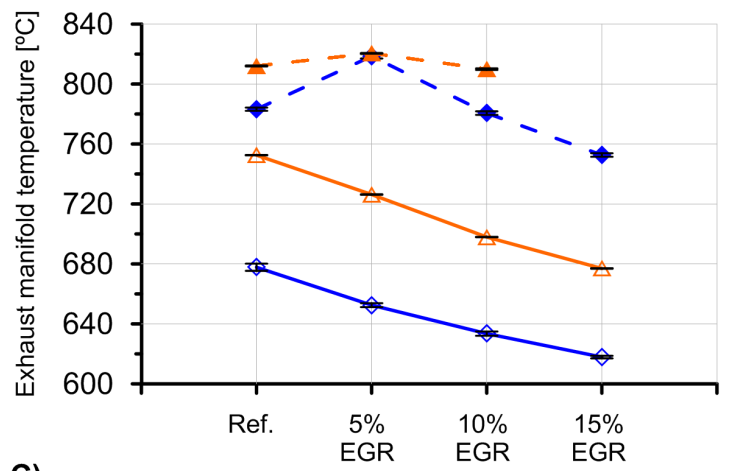

C)

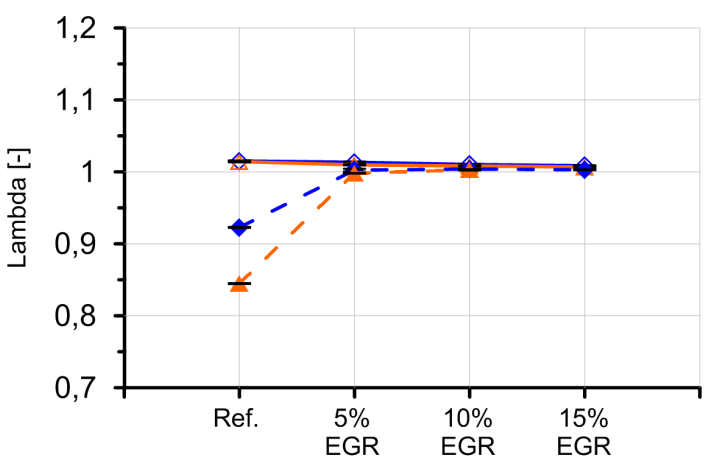

D)

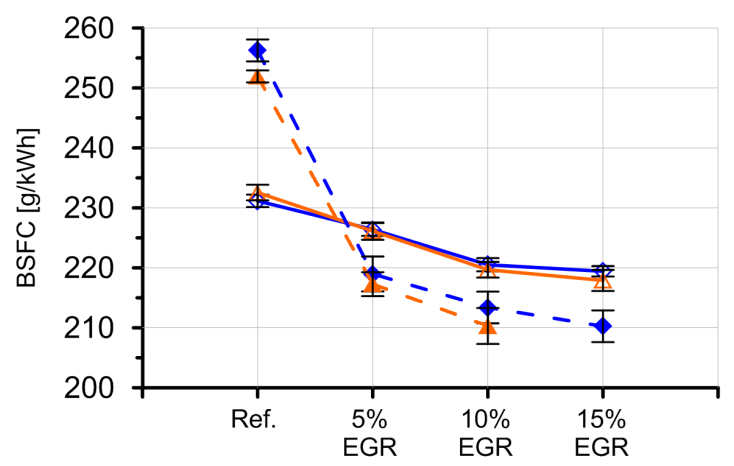

Figure 7: Engine performance at different EGR rate at each steady-state operating points. A) Spark-plug timing. B) Exhaust manifold temperature. C) Lambda. D) BSFC. 
A)
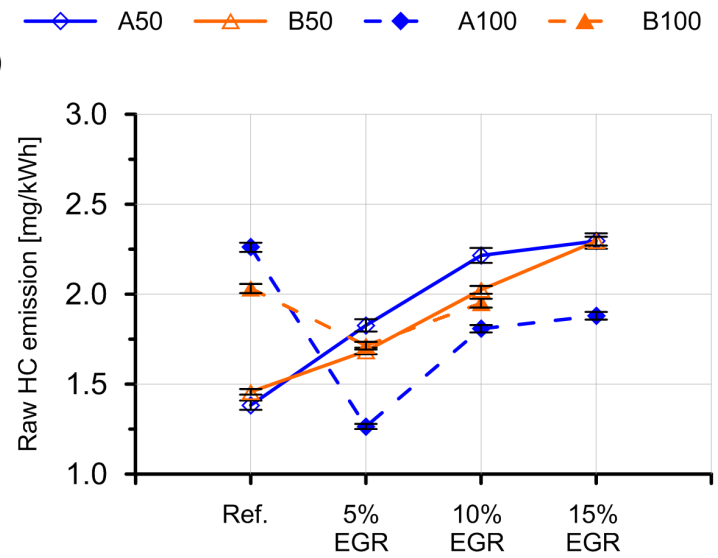

B)

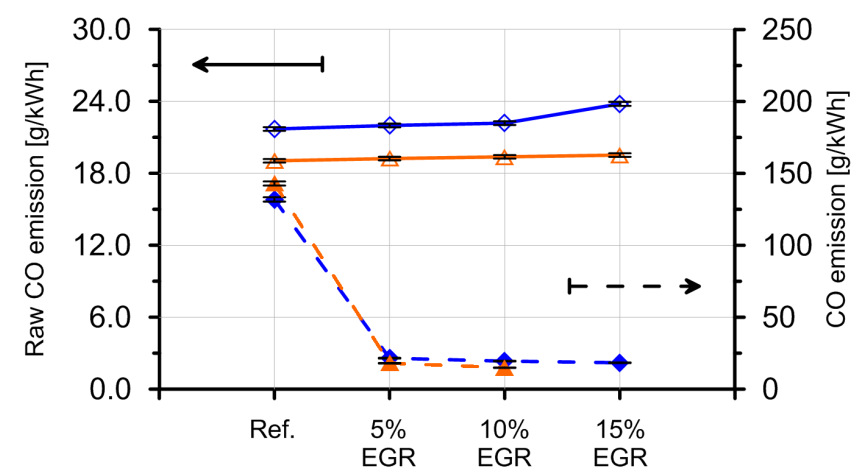

C)

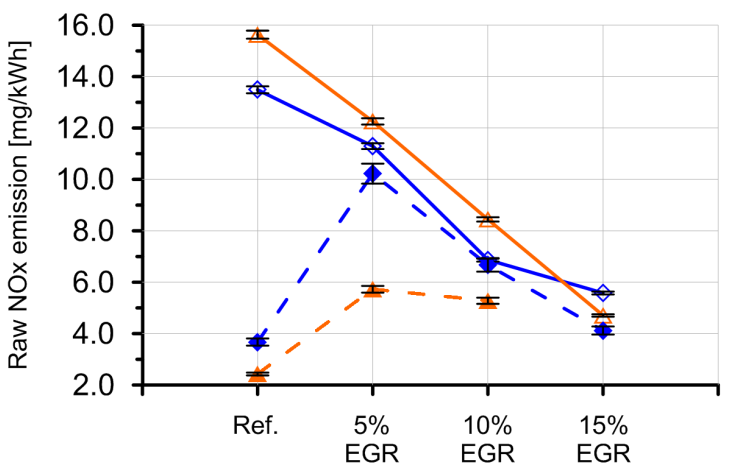

Figure 8: Raw gaseous emission for different EGR rate at each steady-state operating points. A) Raw HC emission. B) Raw CO emission. C) Raw NOx emission. 


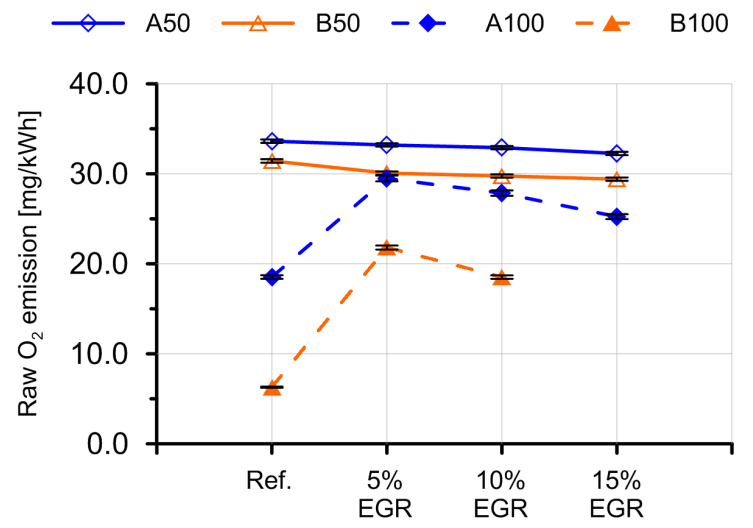

Figure 9: Oxygen content in the exhaust gas upstream the TWC. 
A.1)

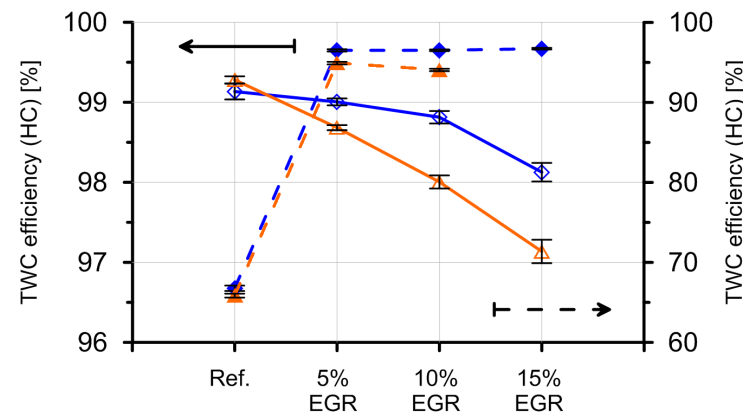

B.1)

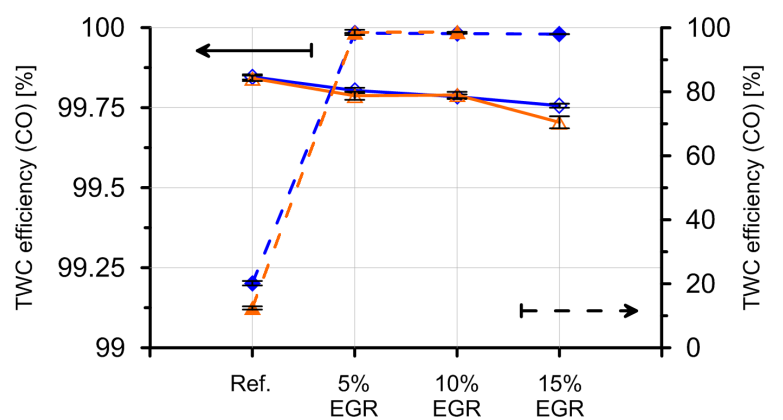

C.1)

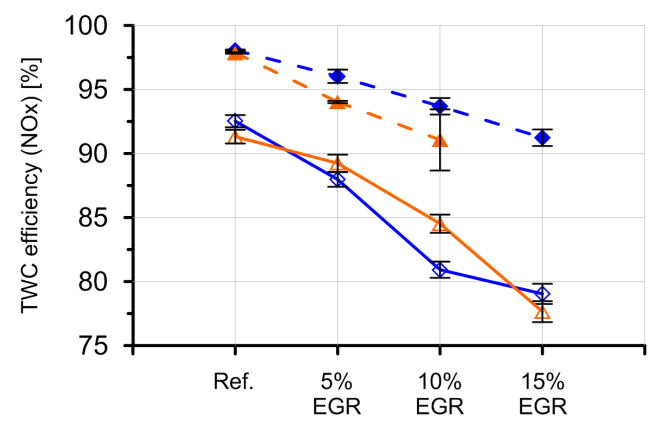

A.2)

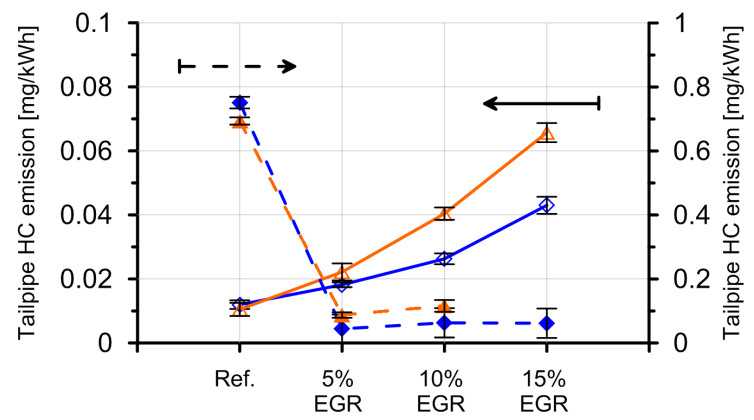

B.2)

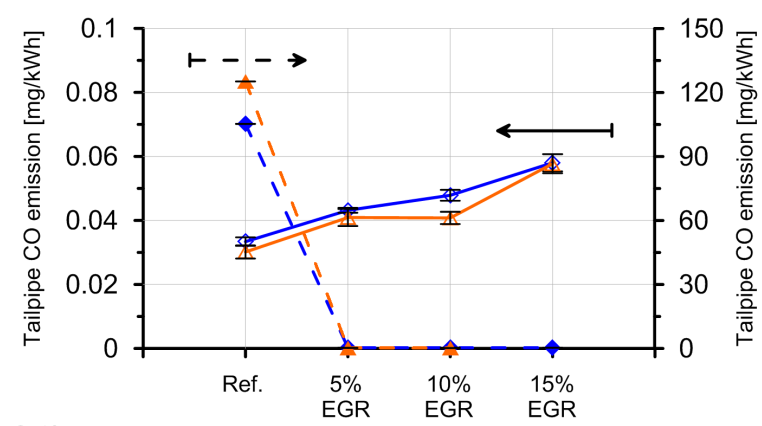

C.2)

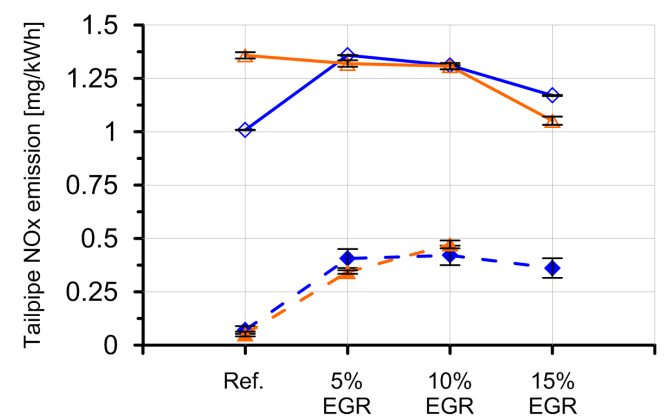

Figure 10: Three way catalyst (TWC) efficiency and tailpipe emissions for different EGR rate at each steady-state operating points. A1) HC efficiency. A2) HC tailpipe emission. B1) CO efficiency. B2) CO tailpipe emission. C1) NOx efficiency. C2) NOx tailpipe emission. 


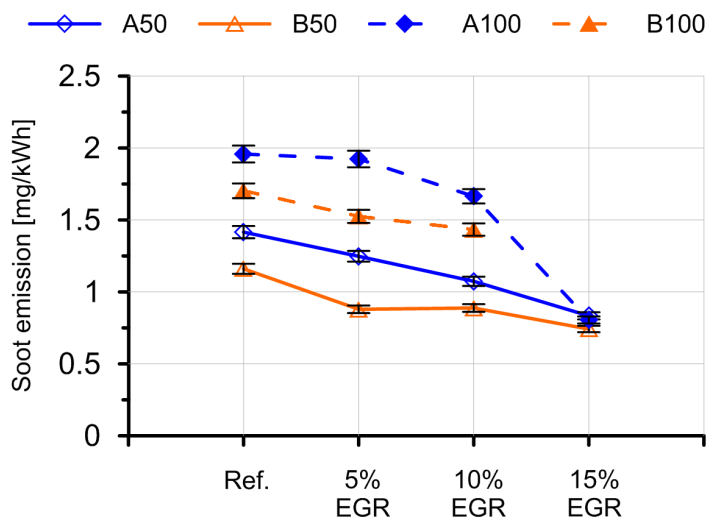

Figure 11: Tailpipe soot emission for different EGR rate at each steady-state operating points.

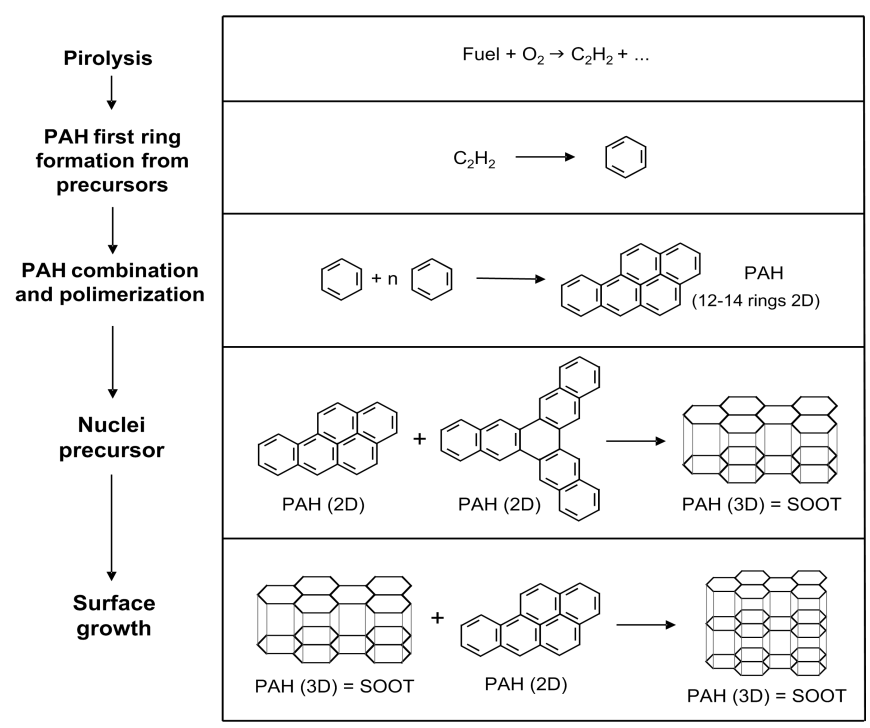

Figure 12: Sketch of soot formation. 
$\longrightarrow$ Reference $\longleftrightarrow$ D EGR $\longleftrightarrow$ E $\longleftrightarrow$ EGR $\longrightarrow$ 10\% EGR

A)

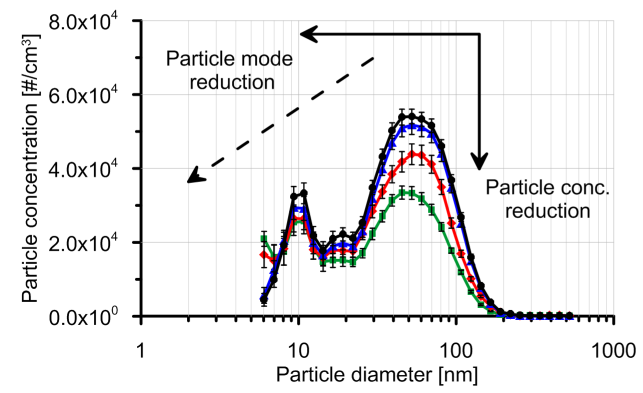

C)

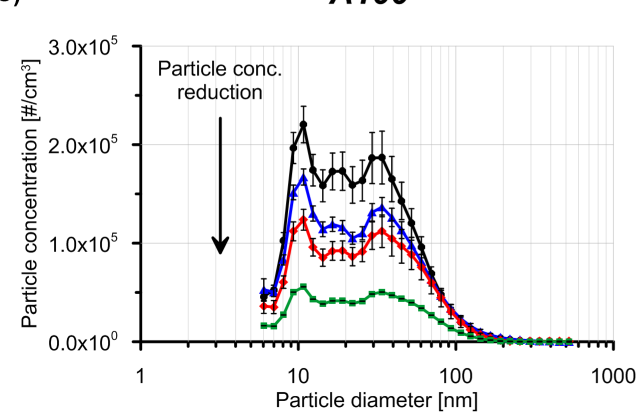

B)

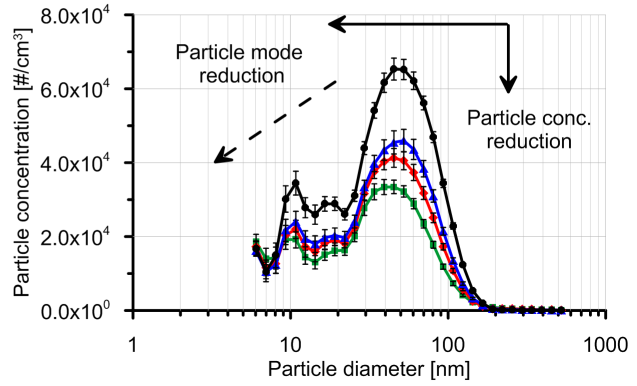

D)

B100

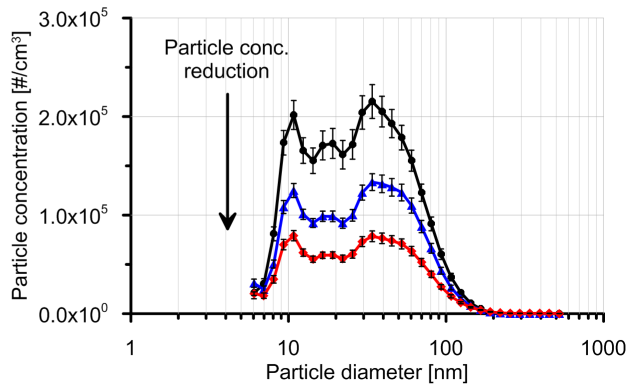

Figure 13: Tailpipe particle size distribution (PSD) for different EGR rates at each steady-state operating points. A) PSD at 2000 rpm medium-load. B) PSD at $3000 \mathrm{rpm}$ medium-load. C) PSD at $2000 \mathrm{rpm}$ full-load. D) PSD at $3000 \mathrm{rpm}$ full-load.
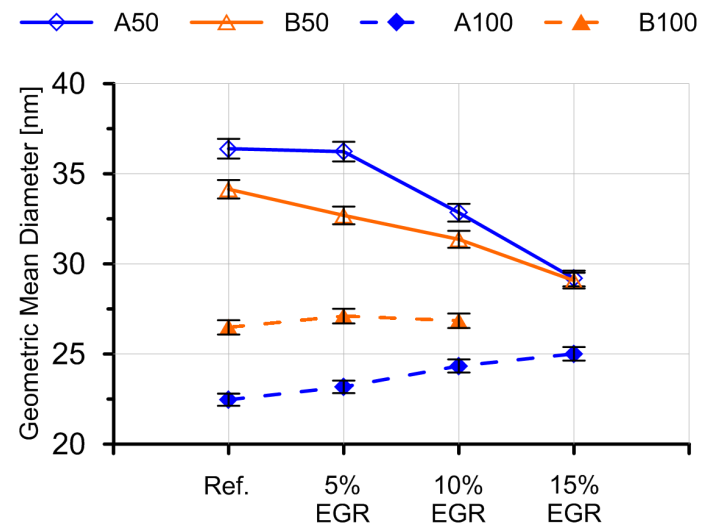

Figure 14: Tailpipe geometric mean diameter (GMD) for different EGR rates at each steady-state operating points.

31 
A)
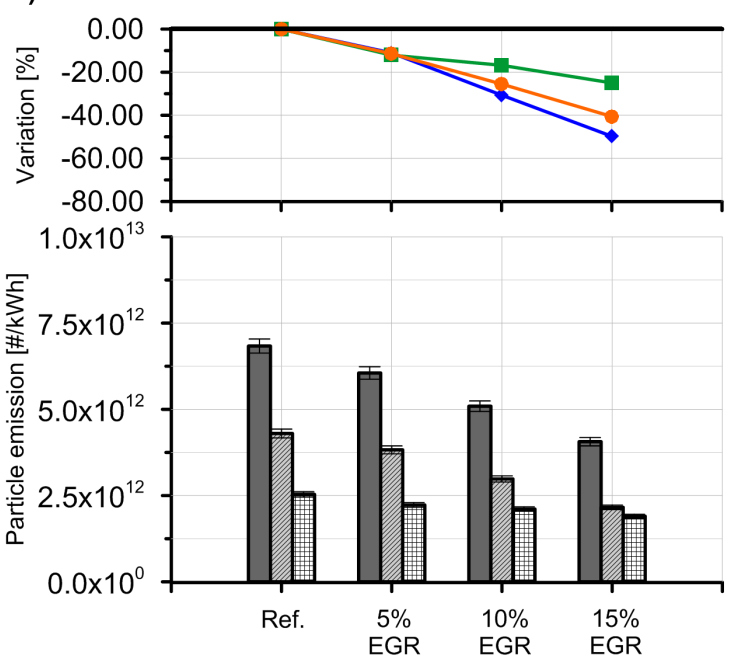

C)
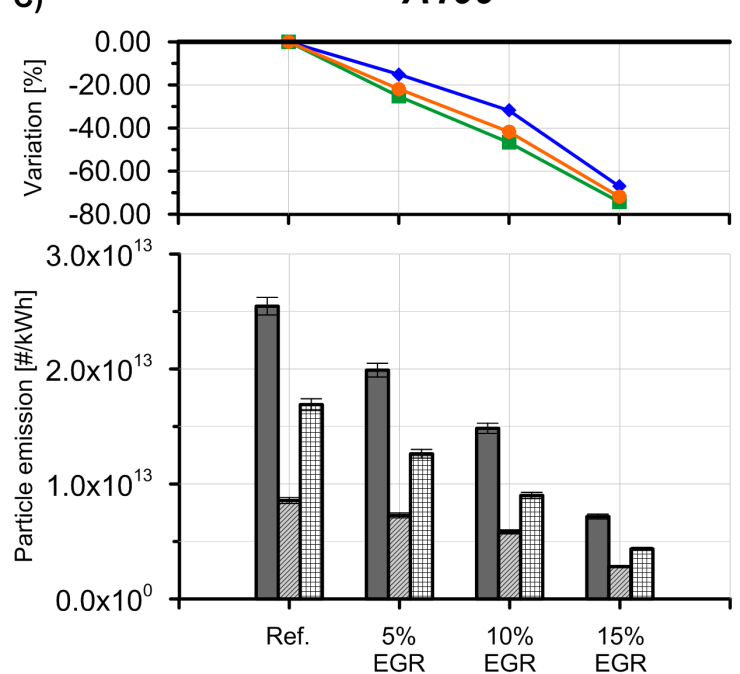

B)
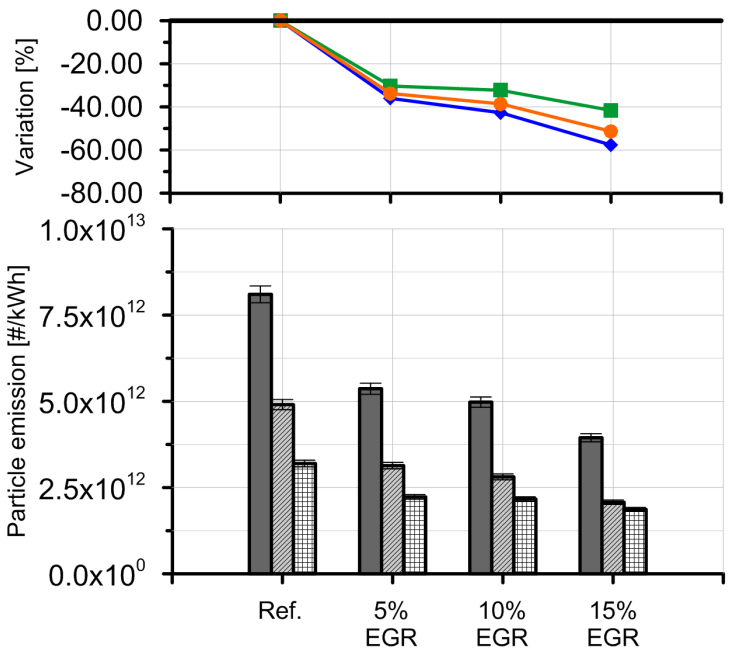

D)
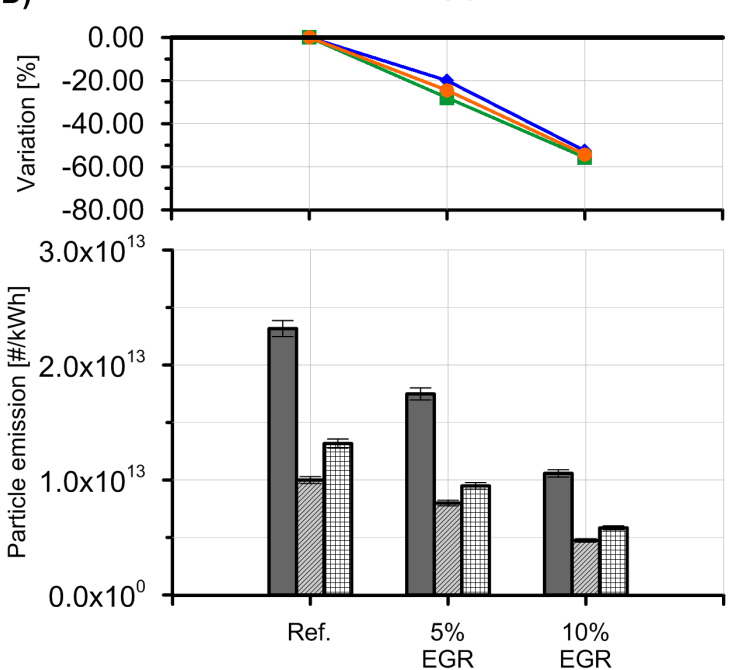

Figure 15: Tailpipe particle composition analysis for different EGR rate at each steady-state operating points. A) Particle composition at $2000 \mathrm{rpm}$ medium-load. B) Particle composition at 3000 rpm medium-load. C) Particle composition at 2000 rpm full-load. D) Particle composition at 3000 rpm full-load. 